\title{
THE SUBFORNICAL ORGAN: A NOVEL SITE FOR PROLACTIN ACTION
}

by

Anusha Kamesh

A thesis submitted to the Department of Neuroscience

In conformity with the requirements for

the degree of Master of Science

\author{
Queen's University \\ Kingston, Ontario, Canada
}

(September, 2017)

Copyright @Anusha Kamesh, 2017 


\begin{abstract}
Prolactin (PRL) is a peptide hormone which performs over 300 biological functions, including those that require binding to prolactin receptor (PRL-R) in neurons within the central nervous system (CNS) (Bole-Feysot, Goffin, Edery, Binart, \& Kelly, 1998). In order to enter the CNS, circulating PRL must overcome the blood-brain barrier. As such, areas of the brain that do not possess a blood-brain barrier, such as the subfornical organ (SFO), are optimally positioned to interact with systemic PRL. The SFO has been classically implicated in energy and fluid homeostasis but has the potential to influence estrous cyclicity and gonadotropin release, which are also functions of PRL. We sought to confirm and characterize the expression of PRL-R in the SFO as well as identify the effects of PRL application on membrane excitability of dissociated SFO neurons. Using real-time quantitative PCR, we identified PRLR mRNA in the SFO in male and female Sprague Dawley rats. PRL-R expression did not significantly differ between males $(n=10)$ and females $(n=24)$, between juveniles $(n=10)$ and sexually mature $(n=24)$ rats, or across the estrous cycle $(n=19)$. Patch-clamp recordings were then obtained using juvenile male rats to further investigate the actions of PRL at the SFO. Dissociated SFO neurons perfused with $10 \mathrm{pM}$ to $1 \mu \mathrm{M}$ PRL resulted in three subpopulations of neurons which either depolarized, hyperpolarized, or did not respond to PRL application $(\mathrm{n}=111)$. The proportion and magnitude of responses were independent of PRL concentration. Furthermore, a majority of SFO neurons showed a reduction in the transient $\mathrm{K}^{+}$ current following PRL exposure. The stability in response to PRL and expression of PRL-R in the SFO suggests PRL function is conserved across physiological states and circulating PRL concentrations, although further studies are required to elucidate the nature of PRL function in the SFO.
\end{abstract}




\section{Co-Authorship}

Data from whole-cell patch-clamp recordings were collected by Emily Black and were used, with permission, for this thesis. 


\section{Acknowledgements}

This is probably the hardest part of my thesis to write because I don't know where to draw the line when thanking people specifically. I guess I'll start off by thanking my mom and dad. You have worked incredibly hard to provide me with the opportunities that led me to pursuing my degrees at Queen's. Thank you for keeping me grounded and for encouraging me in science and in my creative pursuits. Thank you for sitting through my presentations and for pretending to understand what prolactin and the subfornical organ are (to be fair, I barely understand it myself).

Next, I'd like thank the Ferguson lab. To Jordan, Pauline, and Nikki, you taught me everything I know about the techniques I used for my thesis (with the confidence of someone far more competent). Thank you for all your patience and insight. To Emily, thanks for letting me distract you when you sat where I do now and I sat elsewhere. Thank you for comforting me when I came home and cried about how unfairly complicated prolactin is. Thank you for letting me live with you this year, it's been a blast and I can only hope that one day we can become friends. Laura, Hanna, Raoni, and Emma: thanks for providing me with countless opportunities to have a great time (including an above-average number of nights karaoke-ing). I honestly could not have functioned without you as friends and enablers. Thank you to Bruno, Nick, and Susan. Your company was unparalleled during those long days in front of the rig (and I promise I'll let you pick the next song). Thank you to Spencer/Sponce/Susponce for being my conference-buddy; I don't think you know vividly I remember the first time I heard you laugh at one of my jokes. Thank you, Sebastian, for all the spontaneous life-chats and debating hypotheticals when I didn't feel like working. Thank you also for suggesting that I buy the Canada 150 train pass because "they're going to sell out fast" was the biggest understatement of the century. Thank you, Kathleen, for all the chocolate - oh god, the chocolate. Most days, it was the single reason I didn't just give up on my research. A sincere thanks to all the people in the CNS and my $4^{\text {th }}$ floor friends, a lot of you were my window into how awesome research could be years ago, and I have gained so much from your continued friendship. Consider this my scribbling in your yearbook to "keep in touch!” 
I guess that's it. Just kidding. Where on Earth would I be without Al Ferguson? It was serendipitous when I first approached you to do a 499 and you said - I'm paraphrasing - "make it quick, I'm leaving for New Zealand." It was through your recommendation that I volunteered in a lab when I visited New Zealand shortly thereafter, and without that experience I wouldn't be planning to head back in a few months for the next chapter of my thesis life. Your guidance over these years was critical to my growth and just plain immaculate; I don't know how you manage to have the correct answer to every question that has been or will ever be asked. Someone should nickname you Owl Ferguson because you're so wise. Thank you, from the bottom of my heart, for allowing me to experience what it's like to be a member of the Ferguson lab family.

There are, of course, some pretty special people who exist outside of my lab bubble. To Emma, Christina, and Natasha; your friendships have carried me through some of the most difficult times of my life. I can't put into words how emotionally vulnerable you've made me in writing this, and for that I don't thank you. I will say, though, that every time I get a chance to talk to you three, I'm reminded, not of how lucky I am to have you in my life (because I think of that all the time), but of how incredibly lucky the world is to have people as good as you in it.

If I've left anyone out, it's because I don't care about you. To everyone else, I won't forget you when I become a stand-up comedian! 


\section{Table of Contents}

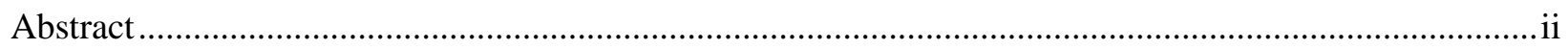

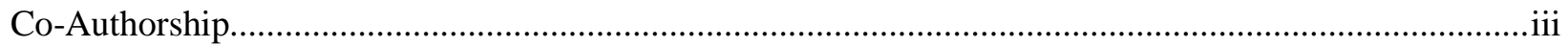

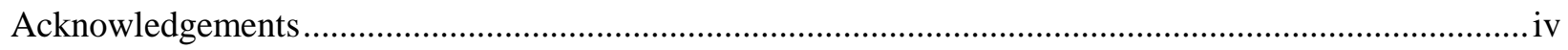

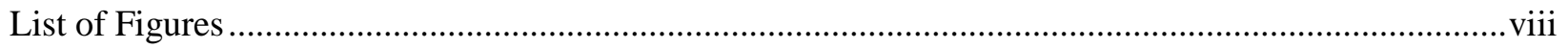

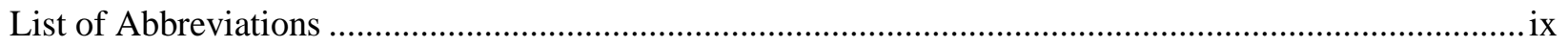

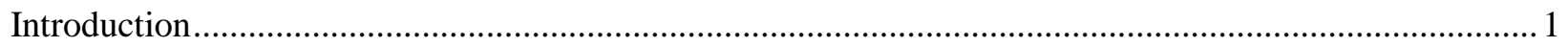

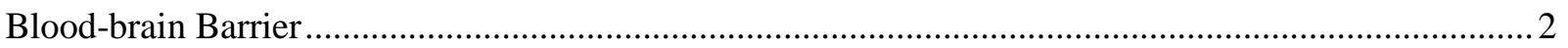

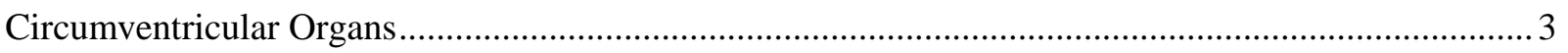

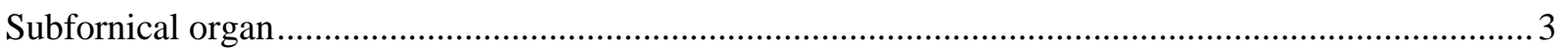

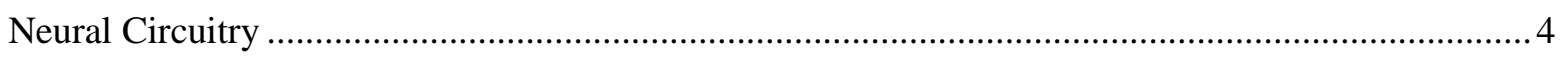

Fluid Balance and Cardiovascular Regulation ......................................................................... 5

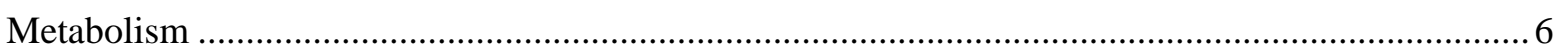

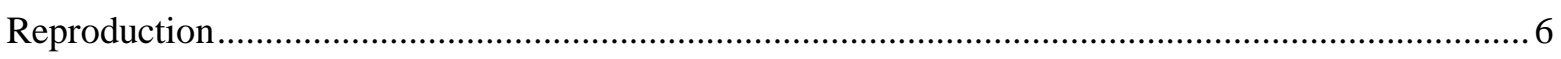

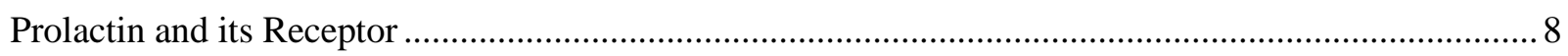

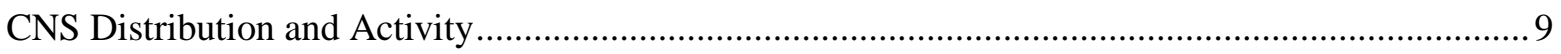

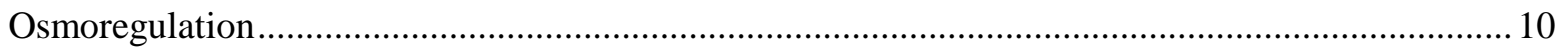

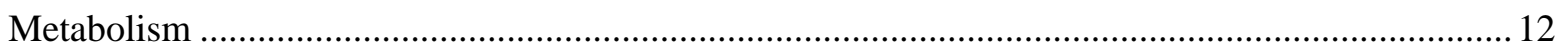

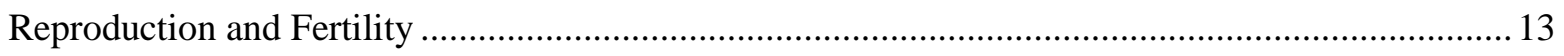

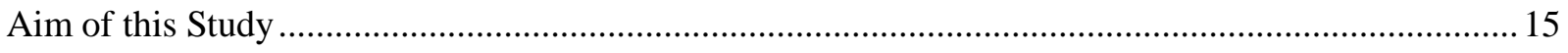

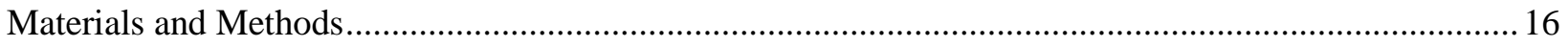

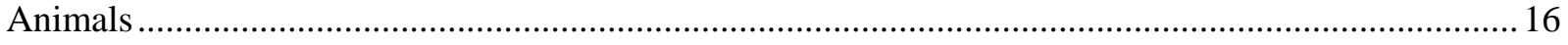

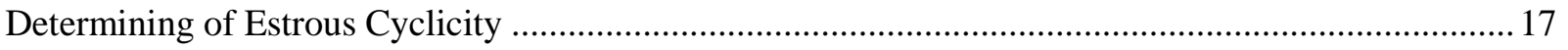

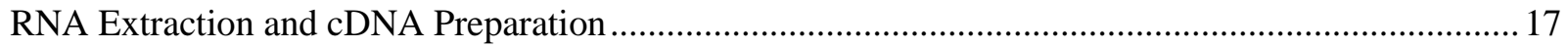

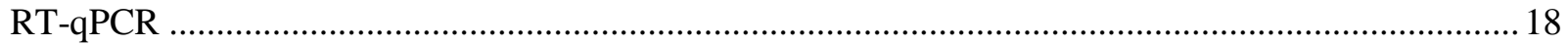

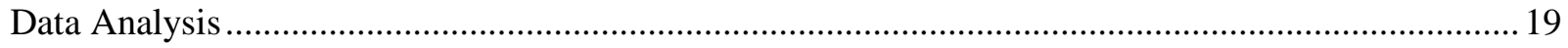

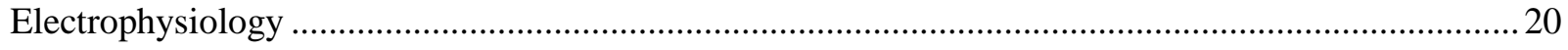

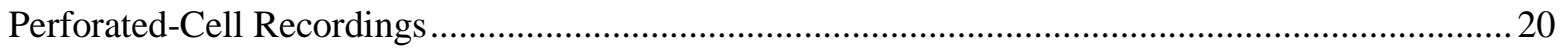

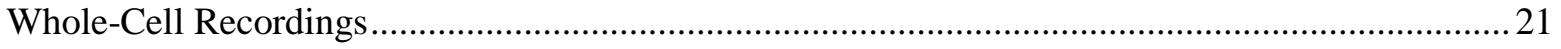

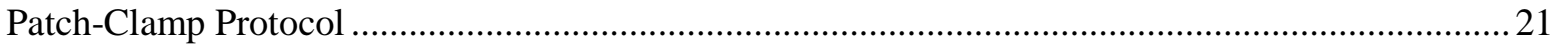

Assessment of the Delayed Rectifier $\mathrm{K}^{+}$and Transient $\mathrm{K}^{+}$Currents ..............................................22

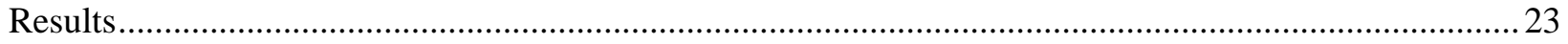

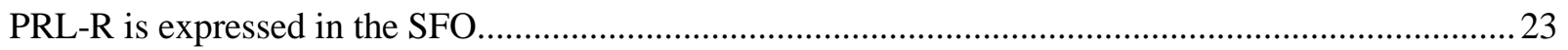


SFO PRL-R expression may occur independently of sexual maturity and sex

SFO PRL-R expression may occur independently of estrous cyclicity ............................................24

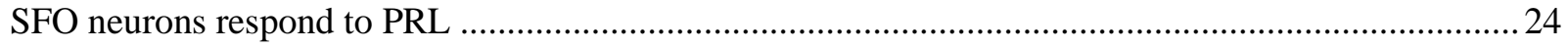

PRL responses were not found to be dependent on PRL concentration .........................................25

PRL responses involve selective reduction of transient $\mathrm{K}^{+}$current ...............................................26

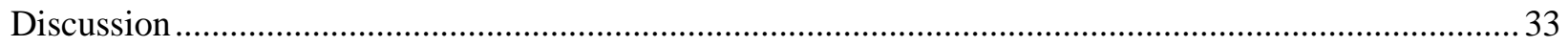

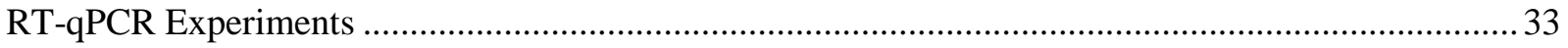

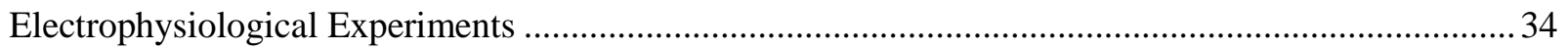

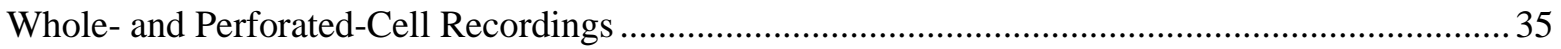

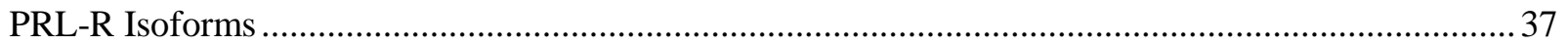

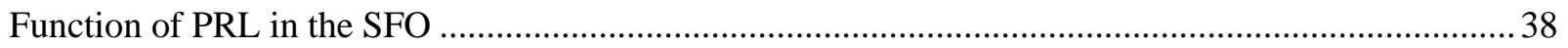

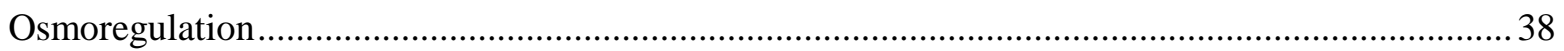

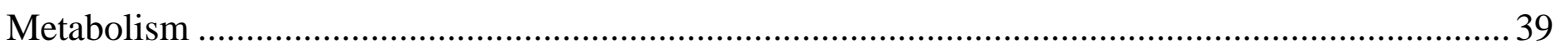

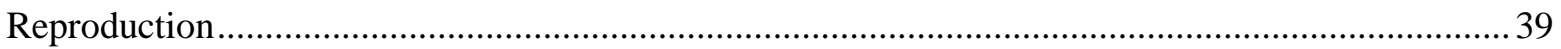

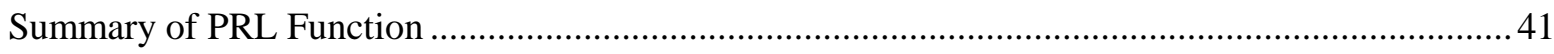

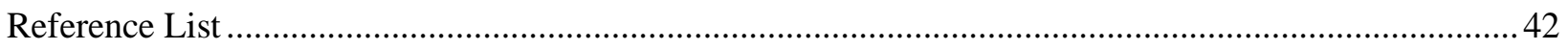




\section{List of Figures}

Figure 1: PRL-R and PGK are expressed in the SFO.

Figure 2: PRL-R and PGK are expressed in the SFO and may be independent of sexual maturity .27

Figure 3: PRL-R and PGK are expressed in the SFO and may be independent of sex...........................28

Figure 4: PRL-R and PGK are expressed in the SFO and may be independent of estrous cyclicity ..........28

Figure 5: PRL affects membrane excitability of SFO neurons ..............................................................29

Figure 6: Responses to PRL may occur independently of PRL concentration ........................................... 30

Figure 7: PRL responses in current-clamp are accompanied by reduction of transient $\mathrm{K}^{+}$current in

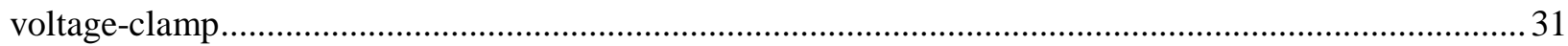

Figure 8: PRL responses in voltage-clamp involve the selective reduction of transient $\mathrm{K}^{+}$current...........32 


\section{List of Abbreviations}

$2^{-\Delta \Delta \mathrm{C}_{\mathrm{T}}}$ Relative mRNA Expression Normalized to Housekeeping Gene

2-APB 2-Aminoethoxydiphenyl Borate

aCSF. Artificial Cerebrospinal Fluid

ACTH. Adrenocorticotropic Hormone

AKT Protein Kinase B

AMPH-B Amphotericin-B

ANF Atrial Natriuretic Factor

ANG Angiotensin II

ARC Arcuate Nucleus

AP Area Postrema

AV3V Anteroventral Third Ventricle

AVPV Anteroventral Periventricular Nucleus

BBB Blood-Brain Barrier

BNST Bed Nucleus of the Stria Terminalis

CCK Cholecystokinin CNS Central Nervous System $\mathrm{CRH}$ Corticotropin-Releasing Hormone $\mathrm{C}_{\mathrm{T}}$ Cycle Number for Threshold Fluorescence CVO Circumventricular Organ

$\mathrm{EC}_{50}$ Half-Maximal Effective Concentration

ERK .Extracellular Signal-Regulated Kinase

GnRH Gonadotropin-Releasing Hormone

ICV. Intracerebroventricular

$\mathrm{I}-\mathrm{V}$ Current-Voltage 
JAK2 Janus Kinase 2

$\mathrm{LH}$ Luteinizing Hormone

MAPK Mitogen-Activated Protein Kinase

$\mathrm{MnPO}$ .Median Preoptic Nucleus

NPY Neuropeptide-Y

NTS Nucleus of the Solitary Tract

OVLT Organum Vasculosum of the Lamina Terminalis

PCR Polymerase Chain Reaction

PI3K Phosphoinositide 3-Kinase

PGK Phosphoglycerate Kinase

PRL Prolactin

PRL-R Prolactin Receptor pSTAT5 Phosphorylated Signal Transducer and Activator of Transcription 5 PVN Paraventricular Nucleus

RT-qPCR Real-Time Quantitative Polymerase Chain Reaction SFO Subfornical Organ SOCS Suppressor of Cytokine Signaling SON Supraoptic Nucleus STAT5 Signal Transducer and Activator of Transcription 5

TIDA Tuberoinfundibular Dopamine

TRH Thyrotropin-Releasing Hormone

TSH Thyroid-Stimulating Hormone

TRP Transient Receptor Potential TTX. Tetrodotoxin $\mathrm{V}_{\mathrm{m}}$ Membrane Potential 


\section{Introduction}

For an animal to obtain healthy physiology, it must work to maintain optimal internal conditions. At a microscopic level, the cellular solution of ions and other small molecules, water, and $\mathrm{pH}$ must be maintained in an optimal composition (Berne, Koeppen, \& Stanton, 2010). This steady-state, termed "homeostasis," should be balanced. Deviations from homeostasis are signaled to, integrated by, and compensated for by the command center, the central nervous system (CNS) (Cannon, 1929). The CNS is able to detect changes in internal homeostasis through a combination of thermoreceptors, chemoreceptors, mechanoreceptors, and receptors for molecular signals such as hormones and neurotransmitters. The CNS is not only able to detect changes in steady-state, but recruits the appropriate mechanism, or effector, which acts to reestablish homeostasis.

Broader physiological functions such as reproduction, immune regulation, and fluid and energy balance are heavily dependent on the cellular environment, and therefore also require feedback onto the CNS (Kennedy, 1950; Merrill \& Jonakait, 1995; Surkin et al., 2017). By assessing parameters such as body temperature, blood pressure and composition, immune state, and nutritional state, the CNS can determine whether it is in good health to carry out energyexpensive functions such as reproduction. Changes to one physiological system often lead to changes in other physiological systems; therefore, it is of critical importance for the CNS to be able to detect extracellular signaling molecules such as hormones and neurotransmitters arising from peripheral organs (termed endocrine), nearby cells (paracrine), or even from its own internal environment (autocrine) (Berne et al., 2010). Our understanding of how the CNS detects local and peripheral signals is paramount to our understanding of how homeostasis is achieved. 


\section{Blood-brain Barrier}

Most molecules in the periphery do not freely diffuse into the brain. Large and lipophobic molecules cannot pass through the overlapping endothelium into the extracellular space that neurons and glia are able to readily access. This filter is referred to as the blood-brain barrier (BBB) and is comprised of the capillary endothelium, a basement membrane, and astrocyte endfeet (Abbott, Ronnback, \& Hansson, 2006).

The BBB functions to maintain the brain's own homeostasis and protect CNS structures from hazardous substances that may be circulating in the systemic blood stream. How, then, is the CNS able to detect a majority of signals originating from the periphery in order to maintain body homeostasis? Indeed, multiple mechanisms allow signaling molecules to overcome the BBB. As alluded to previously, diffusion across the large surface area of the endothelial lipid membrane is one such mechanism, allowing for the passage of lipid-soluble, non-polar agents. The endothelium also possesses transport proteins - both passive and active - for glucose, some amino acids, nucleobases, etc. (as reviewed in Abbott et al., 2006). Some proteins such as insulin and leptin cross the BBB through receptor-mediated endocytosis (Golden, Maccagnan, \& Pardridge, 1997; Gray, Aylor, \& Barrett, 2017). Proteins can also be altered from their native state to increase absorption through the endothelium; this mechanism, termed adsorptive-mediated transcytosis, is often exploited for the delivery of drugs into the CNS (Matthes et al., 2011). Receptors located on the luminal surface of the endothelium may also initiate signaling pathways directly, as is the case for angiotensin II (ANG) at the nucleus of the solitary tract (NTS) (Paton et al., 2001; Paton, Wang, Polson, \& Kasparov, 2008). The aforementioned mechanisms allow selective passage of a minority of circulating molecules and do not account for the feedback of most circulating signals onto the brain. One solution to how these signals overcome the BBB is through interacting with regions of the brain where the BBB does not exist. 


\section{Circumventricular Organs}

Circumventricular organs (CVOs) are regions of the brain in which the capillary endothelium is fenestrated (loosely spaced) to allow for the passage of large molecules between endothelial cells that would otherwise be blocked from entry. In other words, CVOs are areas of the brain lacking a BBB and are therefore ideally located to interact with all circulating signals from the periphery (Ganong, 2000). Sensory CVOs are comprised of the subfornical organ (SFO), the organum vasculosum of the lamina terminalis (OVLT), and the area postrema (AP). These regions of the brain are highly vascularized and contain receptors for temperature and acidity, and can also monitor fluid volume, reproductive and metabolic state, as well as immune status (Ikezu, 2016). CVOs which permit the passage of peptides from nerve terminals to the peripheral blood stream are referred to as secretory CVOs, and include the median eminence, pineal gland, subcommisural organ, and neurohypophysis. Sensory and secretory CVOs differ in morphology and function. The vasculature of the secretory CVOs is different to that of the sensory CVOs; a higher permeability for low-molecular-mass molecules is found in secretory CVOs, presumably to allow the passage of large quantities of peptides released into the blood stream at those locations (Morita \& Miyata, 2012). Sensory CVOs, on the other hand are differentiated by their extensive efferent projections to other brain regions such as regions of the hypothalamus including the supraoptic nucleus (SON), paraventricular nucleus (PVN), and median preoptic nucleus (MnPO), limbic and peri-limbic structures such as the bed nucleus of the stria terminalis (BNST), and ventral pallidum, and regions of the brainstem such as the dorsal raphe nucleus (Sisó, Jeffrey, \& Gonzalez, 2010). In addition, projections between sensory and secretory CVOs allow for direct communication between areas of the CNS that detect changes in homeostasis and areas that correct for these changes.

\section{Subfornical organ}

The SFO, one of three sensory CVOs, is located ventral to the fornix and protrudes out of the rostral wall of the third ventricle. In rats, the SFO is comprised of an outer dorsal shell and an 
inner ventromedial core which houses a dense capillary network (Shaver, Sposito, \& Gross, 1990; Sisó et al., 2010). More generally, the SFO can be subdivided into the rostral, central, and caudal regions. The rostral region is comprised of squamous and cuboidal epithelium. Other cells found in this region include ependymal tanycytes and, to a lesser extent, glial cells. The vasculature in this region is comprised primarily of large venules. The central region contains most of the neuronal perikarya and glial cells located immediately underneath the ependymal surface. The capillary network in this region contains a dense network of primarily fenestrated capillaries. Instead of the lumen of the third ventricle, the caudal region of the SFO abuts a layer of vascularized pia matter on which the choroid plexus resides. While nerve fibers and associated glial cells are found in this region, neuronal perikarya are fewer in number than any other region of the SFO (Dellmann \& Simpson, 1976).

\section{Neural Circuitry}

The ability of the SFO to detect peripheral signals is substantiated by the elaborate efferent neural circuitry. Initial anterograde labelling studies, substantiated by horse-radish peroxidase retrograde staining, determined major efferent output to be brain regions involved in the control of body water (Miselis, Shapiro, \& Hand, 1979). These experiments found major projections to the MnPO and the OVLT. The MnPO and OVLT are found in the anteroventral periventricular area of the third ventricle $(\mathrm{AV} 3 \mathrm{~V})$, and lesions of this region lead to adipsia (Johnson, 1985). Another study found bilateral projections between the SFO and the midbrain raphe system, suggesting the SFO receives visceral sensory information, perhaps relating to blood pressure (Johnson \& Gross, 1993). Additional projection sites identified through anterograde tracing experiments implicated the magnocellular neurons of the SON and PVN (Kawano \& Masuko, 2010; Miselis et al., 1979; Miselis, 1981). These oxytocinergic and vasopressinergic neurons are important for fluid balance, but are also implicated in the stress and reproductive axes. The SFO also innervates the parvocellular division of the PVN which contain pre- 
autonomic neurons projecting to the brainstem, as well as neuroendocrine cells which produce corticotropin releasing hormone $(\mathrm{CRH})$ and thyrotropin releasing hormone (TRH) (as reviewed in Swanson \& Sawchenko, 1983). These hormones act to regulate the release of anterior pituitary hormones such as adrenocorticotropic hormone (ACTH), thyroid stimulating hormone (TSH), and prolactin (PRL) (Harris et al., 1978; Kawano \& Masuko, 2010). In addition, the SFO was found to project to the arcuate nucleus (ARC), which contain populations of neurons involved in feeding and reproductive pathways (Cowley et al., 2001; Franceschini et al., 2006; Plant et al., 1978; Rosas-Arellano, Solano-Flores, \& Ciriello, 1996). This positions the SFO to be an integrator for regulation of neuroendocrine factors involved in the reproductive and feeding axes in addition to its involvement to regulate fluid homeostasis.

\section{Fluid Balance and Cardiovascular Regulation}

The predominant function of the SFO is to regulate fluid homeostasis. This highly

vascularized CVO possesses fenestrated capillaries and is optimally placed to detect blood-borne fluid homeostatic signals such as ANG. In fact, the SFO is the primary CNS site of action for peripheral ANG (Gutman, Ciriello, \& Mogenson, 1988). ANG acts at the SFO to depolarize neurons which project to vasopressinergic PVN and SON neurons as well as the sympathoexcitatory neurons of the MnPO (Gutman et al., 1988; Ono, Honda, \& Inenaga, 2001). This leads to an increase in blood pressure and concomitant increase in water intake (Mangiapane \& Simpson, 1980; Simpson, Epstein, \& Camardo, 1978).

Other hormones also act at the SFO to regulate fluid homeostasis by means of cardiovascular function. These hormones include atrial natriuretic factor (ANF), vasopressin, and endothelin. ANF, produced by the heart, acts at the SFO to antagonize the pressor effects of depolarized SFO neurons (Antunes-Rodrigues, McCann, Rogers, \& Samson, 1985; Hattori, Kasai, Uesugi, Kawata, \& Yamashita, 1988). Endothelin activates PVN- and SON-projecting SFO neurons which in turn secrete oxytocin and vasopressin (Wall \& Ferguson, 1992). 
Vasopressin also influences the excitability of SFO neurons, with a majority of neurons depolarizing (and a subset of neurons hyperpolarizing) to vasopressin bath application (Washburn, Beedle, \& Ferguson, 1999). The actions of ANG, ANF, endothelin and vasopressin, in conjunction with the activation of brainstem neurons which increase vascular tone, implicate the SFO in the regulation of fluid volume, osmolarity, and electrolyte composition.

\section{Metabolism}

In addition to fluid balance and cardiovascular regulation, the SFO has also been implicated in energy balance and metabolism. The SFO expresses receptors for and responds to a variety of metabolic signals including amylin, leptin, ghrelin, glucose and cholecystokinin (CCK) (Ahmed, Dai, Ho, Ferguson, \& Sharkey, 2014; Hindmarch et al., 2008; Medeiros, Dai, \& Ferguson, 2012; Pulman, Fry, Cottrell, \& Ferguson, 2006). Recent evidence has supported the idea that the SFO can integrate both cardiovascular and metabolic signals, as subpopulations of SFO neurons respond to both ANG and the gut hormone CCK. In addition, the proportion of ANG-responsive neurons was shown to be influenced by glucose levels (Cancelliere \& Ferguson, 2017).

Behaviourally, electrical stimulation of the SFO can induce feeding in satiated animals (Smith, Rozanski, \& Ferguson, 2010), which may implicate afferents from the SFO that innervate ARC and lateral hypothalamic neurons that contribute to feeding behaviour (Miselis, 1981). Simultaneous lesioning of the SFO and AP resulted in decreased body weight and food intake (Baraboi, Smith, Ferguson, \& Richard, 2010), further indicating a role for the SFO in metabolic function.

\section{Reproduction}

The SFO possesses receptors for estrogen primarily localized to the periphery, with less extensive localization in the core region. A small proportion of peripheral SFO neurons were colabelled for estrogen receptor and the ANG receptor, $\mathrm{AT}_{1} \mathrm{R}$ (Rosas-Arellano, Solano-Flores, \& 
Ciriello, 1999). Functionally, estrogen reduces the drinking response elicited by ANG, both directly through decreasing the activity of ANG-activated SFO neurons, and indirectly through decreased activation of SFO-projecting angiotensinergic neurons of the lateral hypothalamus (Fujisawa, Tanaka, \& Nomura, 2001; Tanaka, Miyakubo, Okumura, Sakamaki, \& Hayashi, 2001). In addition, approximately 5\% of magnocellular neuron-projecting SFO neurons were shown to express estrogen receptors (Voisin, Simonian, \& Herbison, 1997). This corroborates results which correlate the menstrual cycle to drinking behaviour (Krohn \& Zuckerman, 1937).

A more direct reproductive role for the SFO can be found in behavioural studies in which the SFO is electrically manipulated. Electrical stimulation of the SFO increased peak luteinizing hormone (LH) levels (Donevan, Van Vugt, \& Ferguson, 1989) and lesioning of the SFO attenuated the follicle-stimulating hormone surge and, more importantly, disrupted estrous cyclicity in a number of animals (Limonta, Maggi, Giudici, Martini, \& Piva, 1981).

SFO function can be altered in physiological conditions of increased metabolic and fluid demand, such as in pregnancy. The hormone relaxin, produced by the corpus luteum in females and the prostate in males, activates SFO neurons and elicits increased drinking behaviour (Otsubo et al., 2010; Sunn et al., 2002). During pregnancy, relaxin increases renal blood flow, cardiac output and increased arterial compliance; some of these functions may be mediated through its ability to antagonize endothelin receptors in the CNS (Conrad, 2011; Dschietzig et al., 2003; Kakouris, Eddie, \& Summers, 1992; Novak et al., 2001). Another reproductive hormone that may signal through the SFO is PRL. The initial evidence in support of PRL actions in the SFO comes from microarray analysis of the SFO transcriptome demonstrating the expression of PRL receptor (PRL-R) in this CVO (Hindmarch et al., 2008). Moreover, PRL-R is also expressed in regions of the hypothalamus that the SFO provides neural efferent connections to; including the ARC nucleus, preoptic area, and the SON (Pi \& Grattan, 1998). Unpublished data from the Grattan lab also identified the activation of the signaling pathway for the PRL-R within the SFO. Little is 
known about the function or the parameters of PRL signaling in the SFO, including the relative expression of PRL-R in the SFO as compared to other hypothalamic nuclei.

\section{Prolactin and its Receptor}

The $23 \mathrm{kDa}$ protein PRL is a pleiotropic hormone produced by the anterior pituitary, with over 300 biological functions. Initially discovered as a blood-borne signal for promoting lactation (Bates \& Riddle, 1935), PRL has since been implicated in maternal behaviour, immune system function, osmoregulation, stress, energy homeostasis, and fertility (Larsen \& Grattan, 2010; Leontic \& Tyson, 1977; McNeilly, Abbott, Lunn, Chambers, \& Hearn, 1981; Rawn et al., 2015; Wu et al., 2014). Regulation of PRL release occurs primarily through negative feedback onto the CNS. Tuberoinfundibular dopamine (TIDA) neurons in the ARC express PRL-R, the activation of which results in the subsequent inhibition of lactotrophic activity in the anterior pituitary and ultimately, decreased secretion of PRL (Lyons, Hellysaz, \& Broberger, 2012; Perkins, Westfall, Paul, MacLeod, \& Rogol, 1979). Moreover, expression of the PRL-R can also be positively regulated by PRL, both in the presence of estrogen and independently (Kavarthapu, Tsai Morris, \& Dufau, 2014).

Circulating PRL levels can change with circadian rhythms, physiological state, sex, and age (as reviewed in Freeman, Kanyicska, Lerant, \& Nagy, 2000). In rodents, circulating PRL is in the range of $5-20 \mathrm{ng} / \mathrm{mL}$ in males. In females, PRL levels prior to puberty are similar to that of males (Ramaley, 1981). After puberty, serum PRL levels depend on the stage of the estrous cycle, with peak levels of 120-150 ng/mL observed in the proestrous stage (Lopez-Fontana, Maselli, de Di Nasso, Telleria, \& Caron, 2011). PRL levels drop in the estrous stage to $60-80 \mathrm{ng} / \mathrm{mL}$ and return to basal levels of $30-60 \mathrm{ng} / \mathrm{mL}$ at the diestrous and metestrous stages (Voogt, Chen, \& Meites, 1970). During pregnancy and lactation, rodents experience blood PRL levels of up to 200-300 ng/mL (as reviewed in Patil, Henry, \& Akopian, 2014). PRL levels also increase during inflammation, and physiological and pathological stress (as reviewed in Freeman et al., 2000). 
PRL is also released from extra-pituitary sources both within and outside of the CNS, which could alter local PRL concentrations.

Given that PRL is a large peptide hormone, it requires transport across the $\mathrm{BBB}$. The principal mechanism by which PRL is thought to enter the CNS is through receptor-mediated endocytosis at the choroid plexus (Walsh, Slaby, \& Posner, 1987). PRL-R is a class one cytokine receptor, closely related to the receptors for growth hormone and placental lactogens. In the rat, PRL-R exists in three isoforms: short, intermediate, and long. Dimerization of the receptor upon binding to PRL results in the activation of Janus kinase 2 (JAK2) and signal transducer and activator of transcription 5 (STAT5) proteins. Phosphorylation of STAT5 into its active form, pSTAT5, results in the transcription of cell-specific genes. The termination of the signal cascade occurs through the activation of the suppressor of cytokine signaling (SOCS) protein, which binds to and inhibits activity of the JAK2-STAT5 complex (as reviewed in Goffin, Binart, Touraine, \& Kelly, 2002). Other signaling pathways include the extracellular signal-regulated kinase (ERK) mitogen-activated protein kinase (MAPK) pathway, the phosphoinositide 3-kinase (PI3K) protein kinase B (AKT) pathway, and the Src tyrosine kinase pathway. PRL-R binding can also lead to alterations of ion transport, as has been identified in the kidney and at the gills of freshand salt-water fish (Breves et al., 2016; Breves, McCormick, \& Karlstrom, 2014; Watanabe, Itoh, \& Kaneko, 2016). The alteration of ion transport in the neurons of the CNS by PRL can result in modulation of electrical activity of neurons; PRL can therefore act as a neurotransmitter and neuromodulator within subpopulations of CNS neurons.

\section{CNS Distribution and Activity}

PRL-R distribution is found throughout the brain. Reverse transcription polymerase chain reaction (PCR) experiments on homogenized mouse brain tissue detected PRL-R mRNA expression in the anterior hypothalamus, medial basal hypothalamus, and the anterior and posterior pituitary gland (Chiu, Koos, \& Wise, 1992). More specifically, immunostaining and in 
situ hybridization experiments identified regions of the forebrain including the ARC, median eminence, the anteroventral periventricular nucleus (AVPV), MnPO, preoptic periventricular nucleus, and medial preoptic nucleus as positive for PRL-R. Immunoreactivity was also found at the choroid plexus of the lateral, third, and fourth ventricles (Brown, Kokay, Herbison, \& Grattan, 2010; Pi \& Grattan, 1998).

Previous research has identified subpopulations of neurons which are activated by the application of PRL. TIDA neurons, for example, altered their oscillating firing state to tonic firing when exposed to $250 \mathrm{nM}$ PRL (Lyons et al., 2012). Additionally, a subpopulation of AVPV neurons increased their firing rate in response to $250 \mathrm{nM}$ PRL (Silveira et al., 2017). Conversely, some oxytocinergic PVN neurons are inhibited by PRL (Sirzen-Zelenskaya et al., 2011). Ion channels mediated by PRL depend on the cell type. In TIDA neurons, the current induced by PRL was attenuated using the transient receptor potential (TRP) channel blocker, 2aminoethoxydiphenyl borate (2-APB), suggesting the involvement of TRP channels in the PRL response. The inhibition of $\mathrm{Ca}^{2+}$-activated $\mathrm{K}^{+}$channels are also a potential mechanism of TIDA neuron depolarization by PRL (Lyons et al., 2012). In addition, $\mathrm{Ca}^{2+}$ levels directly may be influenced by PRL, as application of $10 \mathrm{ng} / \mathrm{mL}$ PRL on cultured hippocampal neurons led to a transient increase in intracellular $\mathrm{Ca}^{2+}$ (Rivero-Segura et al., 2017).

\section{Osmoregulation}

While it was initially discovered for its ability to promote lactation, a large body of PRL research uses non-mammalian models, including fish and amphibians. Osmoregulation through modulating ion and water levels are dependent on PRL action in both fresh-water and salt-water fish (as reviewed in Bern, 1975). The exact mechanisms by which PRL modulates hydromineral status, however, are species-dependent. In freshwater tilapia as well as in the newt, hypophysectomy decreased $\mathrm{Na}^{+}$retention, while PRL re-administration was able to partially rescue $\mathrm{Na}^{+}$levels (Brown \& Brown, 1973; Dharmamba \& Maetz, 1972). In the sea bream, which 
is able to tolerate a range of salinity, PRL induced hypernatremia through sodium retention (Sangiao-Alvarellos et al., 2006). In fresh water tilapia, in which PRL administration also increased water retention, the transcription of PRL-R was correlated to the transcription of aquaporin 3 and several $\mathrm{Na}^{+}$transporters (Moorman et al., 2014). Conversely, in goldfish, water influx was inhibited by PRL administration (Ogawa, Yagasaki, \& Yamazaki, 1973).

Despite the limitation of species-specificity, research in PRL actions in non-mammalian models can be translated to mammalian and human physiology. Hydromineral status is critical for pregnant females to be able to remain in good health while their bodies are losing ions and water to the fetus and through breastmilk. The fetus itself may be dependent on PRL for fluid homeostasis. In the human amnion, PRL administration, specifically to the fetal side, decreased permeability and therefore increased fluid retention (Leontic \& Tyson, 1977). Research on PRL actions in the osmoregulation of mammary epithelium are lacking, as evidence for this function of PRL comes from model systems in fish and cultured mammary epithelium-like cells (as reviewed in Bern, 1975).

Ion and fluid balance through PRL have been implicated in other tissue in non-pregnant mammals. Ion transport across the proximal and distal colon as well as in the kidney suggest that PRL reduces the secretion of $\mathrm{Ca}^{2+}$ - dependent $\mathrm{Cl}^{-}$and $\mathrm{K}^{+}$in the colon and water, $\mathrm{Na}^{+}$, and $\mathrm{K}^{+}$ excretion in the kidney (Horrobin et al., 1971; Puntheeranurak et al., 2007). More grossly, PRL may be implicated in fluid intake, as PRL secretion is stimulated by intra- and extracellular deficits and works to potentiate the dipsogenic actions of sub-threshold levels of ANG (Kaufman, 1981; Kaufman \& Mackay, 1983). PRL therefore regulates hydromineral status is a variety of animals, and in many cases, requires concomitant regulation of energy reserves, as would be required during pregnancy and lactation. 


\section{Metabolism}

The link between PRL and metabolism is most obvious in lactation; fat, lactose, and protein content in the breastmilk must be regulated to support the nutritional demands of the offspring. Once again, a large body of PRL research related to metabolism comes from nonmammalian species. In the sea bream, in addition to actions on osmoregulation, PRL increased glucose availability in the kidney and the brain (Sangiao-Alvarellos et al., 2006). In salmon, PRL stimulated lipid mobilization and increased lipase activity (Sheridan, 1986). In the chick, PRL administration increased the short term metabolism of vitamin $\mathrm{D}_{3}$ (Spanos et al., 1976).

PRL actions on metabolism have also been characterized in mammals. As reviewed by Ben-Jonathan et al.(2006), PRL can affect the synthesis of milk constituents such as proteins, lactose and lipids by increasing the synthesis of $\beta$-casein and $\alpha$-lactalbumin, increasing glucose uptake and lactose synthesis, and by increasing the activity of enzymes such as lipoprotein lipase, pyruvate dehydrogenase, and acetyl-coA carboxylase. PRL also has been implicated in regulating insulin secretion. Physiologically, PRL is an important mediator of glucose homeostasis during gestation, as would be required by the increased energy demand of gestation, parturition, and lactation.

Moreover, this implicates PRL in energy homeostasis in other physiological and pathophysiological states. In diabetic rats, high doses of PRL exacerbated insulin resistance and altered $\beta$-cell mass compared to control animals (Park, Kang, Lee, \& Ko, 2012; Park, Kim, Daily, \& Kim, 2011). Increased body mass in humans is positively associated with serum PRL as reducing PRL levels in hyperprolactinemic patients was correlated with decreased body mass (Greenman, Tordjman, \& Stern, 1998). Interestingly, central administration of PRL in virgin female rats resulted in hyperphagia (Sauvé \& Woodside, 1996). This physiological response is site-specific as only PRL injected in the PVN induced hyperphagia in these animals, implicating PRL in the hypothalamic control of feeding (Sauvé \& Woodside, 2000). PRL may achieve this 
effect, both during and outside of pregnancy through its interactions with other metabolic hormones; double-labelling experiments colocalized PRL-activation and leptin-receptor expression in the subpopulations of neurons in the medial preoptic area, the retrochiasmatic area, and the NTS (Nagaishi et al., 2014). In the male ring dove, PRL-induced hyperphagia was accompanied by increased neuropeptide-y (NPY)-irradiated cell bodies in the infundibular region, suggesting that PRL-induced hyperphagia is mediated, at least in part, by the actions of the feeding hormone NPY (Strader \& Buntin, 2001). PRL may therefore promote the intake and mobilization of nutrients in both males and females, and more importantly, in preparation for reproductive function.

\section{Reproduction and Fertility}

PRL's actions as a reproductive hormone are perhaps its most apparent function. Not only is PRL and PRL-R reproductive function characterized in animal models, but has been extensively implicated in clinical studies on reproduction and fertility in humans. As reviewed by Egli et al. (2010), PRL secretion patterns have been implicated both in fertility, reproductive function, and sexual satiation. In rodents, PRL levels depend on the stage of the estrous cycle with peak PRL levels occurring at the proestrous PRL surge. In humans, a PRL surge is coincident with the LH surge, however, variation in serum PRL is much less in human females than in rodents. The coincident LH surge itself may be regulated by PRL, as intracerebroventricular (ICV) PRL injection acutely disrupts LH pulsatility through activity of the PRL-R (Grachev, Li, Goffin, \& O’Byrne, 2015). The suppression of LH levels is, in part, a result of altered signaling in gonadotropin releasing hormone (GnRH) neurons (Grattan, Jasoni, Liu, Anderson, \& Herbison, 2007). This mechanism could explain the prevalence of infertility in patients with hyperprolactinemia. Treatment with bromocriptine, an inhibitor of endogenous PRL secretion, resulted in a higher percentage of successful pregnancies in women with hyperprolactinemia (Hirahara et al., 1998). In physiological states with increased PRL levels, 
such as during lactation, fertility is reduced. However, the link to PRL remains controversial as studies have also found a lack of correlation between PRL and infertility (McNeilly et al., 1981; Tay, Glasier, \& McNeilly, 1996). Our understanding of PRL regulation of fertility is further complicated by the fact that PRL-R knockouts and clinical studies with hypoprolactinemia also result in impaired fertility, and that this impairment can be restored with normalization of PRL levels (Kauppila, Chatelain, Kirkinen, Kivinen, \& Ruokonen, 1987; Otto et al., 2015). In males, PRL may indirectly impact fertility as it has been implicated in the maintenance of accessory reproductive gland function, as well as the maintenance and development of the prostate gland (Bartke, 1974; Leav et al., 1999; Wennbo, Kindblom, Isaksson, \& Tornell, 1997). It therefore seems that both over- and under-secretion of PRL can result in infertility, primarily in females.

Regulation of PRL secretion also involves other reproductive hormones. In addition to the negative feedback by dopamine, positive feedback from oxytocin and estrogen have been shown to increase PRL levels (Helena et al., 2011; Raymond, Beaulieu, Labrie, \& Boissier, 1978). Incubation with estrogen also promotes PRL-R mRNA expression (Pi, Zhang, Li, \& Voogt, 2003). Estradiol arising from breast and adipose tissue can mediate the transcription of the human PRL-R and may therefore contribute to normal and pathogenic development of breast tissue (Dong, Tsai-Morris, \& Dufau, 2006). Even exclusively within the scope of reproductive function, it becomes apparent the complexity of PRL actions within the body. Along with other actions of this pleiotropic hormone, a substantial area of interest arises in determining the mechanisms underlying the many functions of PRL. 


\begin{abstract}
Aim of this Study
The position of the SFO outside of the BBB makes this CVO an ideal site for interactions with the $23 \mathrm{kDa}$ peptidergic hormone PRL. We tested our hypothesis that PRL-R is expressed at the SFO and that expression of the receptor is dependent on both sex and sexual maturity. We also hypothesized that PRL-R expression is dependent on the stage of the estrous cycle of the animal. To test these hypotheses, we used real-time quantitative PCR (RT-qPCR). The second aspect of our experiments was to test the hypothesis that PRL signals through neurons of the SFO by modulating membrane excitability; this was tested using patch-clamp electrophysiology on dissociated SFO neurons.
\end{abstract}

The aim of this study was therefore to further characterize PRL function by identifying a mechanism by which PRL acts through neurons of the SFO. 


\section{Materials and Methods}

\section{Animals}

Experimental procedures were approved by the Queen's University Animal Care Committee and in accordance with the Canadian Council on Animal Care guidelines. Sprague Dawley rats were purchased from Charles River Laboratories (Montreal, QB, Canada) and were housed in pathogen-free conditions at the Queen's Animal Care facility under a 12:12-h lightdark cycle with access to food and water ad libitum.

SFOs were dissected from male and female juvenile rats aged 27-35 days (weighing 50$75 \mathrm{~g}$ ), and from male and female sexually mature rats aged 3 months (weighing 250-400g). Due to the small size of the SFO, tissue from three rats was pooled for each experiment. A previously described protocol for SFO dissociation was followed for electrophysiological recordings (Ferguson, Bicknell, Carew, \& Mason, 1997); the same protocol was modified for RT-qPCR. Brains were collected and transferred to ice-cold artificial cerebrospinal fluid (aCSF) comprised of $140 \mathrm{mM} \mathrm{NaCl}, 5 \mathrm{mM} \mathrm{KCl}, 1 \mathrm{mM} \mathrm{MgCl} 2,2 \mathrm{mM} \mathrm{CaCl}_{2}, 10 \mathrm{mM}$ HEPES, $5 \mathrm{mM}$ mannitol, and 5 $\mathrm{mM}$ glucose. Under a microscope, the cortex was cut away and the hippocampal commissure was separated out. Following removal of overlaying choroid plexus tissue, three SFOs were placed in microcentrifuge tubes containing $500 \mu \mathrm{L}$ of QIAzol Lysis Reagent (Qiagen, Toronto, ON) and vortexed to homogenize the tissue for RT-qPCR. For electrophysiology, SFOs were placed in Hibernate-A media (ThermoFisher, Toronto, ON) containing B-27 supplement (GIBCO, Gaithersburg, MD). Three SFOs were then transferred to a solution containing $10 \mathrm{mg}$ of papain (lyophilized; Worthington Biochemical, Lakewood, NJ) in $5 \mathrm{~mL}$ of Hibernate-A and incubated at $31^{\circ} \mathrm{C}$ for $30 \mathrm{~min}$. SFOs were rinsed with Hibernate-A/B-27 solution and gently triturated until tissue was no longer visible and centrifuged at $8 \mathrm{~min}$ at $200 \mathrm{rpm}$ to pellet the dissociated neurons. The supernatant was carefully removed and the pellet resuspended in Neurobasal-A media (Thermo Fisher Scientific, Waltham, MA) - originally D-glucose- and sodium pyruvate-free - 
supplemented with B-27, $227 \mu \mathrm{M}$ sodium pyruvate (ThermoFisher, Toronto, ON), $100 \mathrm{U} / \mathrm{mL}$ penicillin-streptomycin (ThermoFisher, Toronto, ON), $0.4 \mathrm{mM} \mathrm{L-glutamine} \mathrm{(ThermoFisher,}$ Toronto, $\mathrm{ON}$ ), and $5 \mathrm{mM}$ glucose. The cell suspension was then aliquoted onto $35-\mathrm{mm}$ tissueculture-treated plastic bottom Corning dishes (Sigma, St. Louis, MO). The plates were incubated for 1.5 hours at $37^{\circ} \mathrm{C}$ to allow the cells to adhere to the plate in an incubator (Forma Scientific, Marietta, $\mathrm{OH})$ that circulated 5\% $\mathrm{CO}_{2}$ balanced with ambient air. Plates were fed with approximately $2 \mathrm{~mL}$ Neurobasal-A solution (described earlier) and were allowed to sit for at least 24 hours before recording.

\section{Determining of Estrous Cyclicity}

Female sexually mature rats underwent vaginal lavage with $50 \mu \mathrm{L}$ of a $0.9 \%$ saline solution to flush out the vagina using a $200 \mu \mathrm{L}$ micropipette, and the resulting collection was placed on a microscope slide, stained with $0.1 \%$ crystal violet, cover-slipped and analyzed under a microscope. Predominant lymphocytes were characteristic of the diestrous stage; nucleated epithelial cells, proestrus; cornified epithelial cells, estrus; and an equal proportion of all three were characteristic of the metestrous stage. The rats were smeared daily until three were in the same stage, then all three were decapitated on the same day.

\section{RNA Extraction and cDNA Preparation}

Total RNA was extracted from the tissue samples using the RNeasy Lipid Tissue Kit (Qiagen, Toronto, ON) following protocol provided by the manufacturer. After lysis and homogenization of the tissue in the QIAzol Lysis Reagent, the sample tubes were placed on the benchtop at room temperature for 5 mins to dissociate nucleoprotein complexes. $200 \mu \mathrm{L}$ of chloroform was added to the tubes, the samples were shaken vigorously for 15 seconds and phase separation began as the samples incubated on the benchtop for an additional 2 mins. The samples were centrifuged for 15 mins at $12,000 \mathrm{x} g$ and the upper phase was transferred to a clean microcentrifuge tube. An equal volume of $70 \%$ ethanol was added and the samples were vortexed 
and transferred to RNeasy Mini spin columns. The samples underwent centrifugation and washed with buffers as specified in the RNeasy Lipid Tissue Kit. The collection of RNA eluted into 30 $\mu \mathrm{L}$ of $37^{\circ} \mathrm{C}$ nuclease-free water was run through spectrophotometry using the Nanodrop ND-1000 (Thermo Scientific, Toronto, ON) to determine purity and concentration. Purity, as determined by A260/A280 values, ranged from 1.7-2.1.

Off-column DNase digests were performed using the Ambion TURBO DNase Kit (ThermoFisher, Toronto, ON). $3 \mu \mathrm{L}$ of TURBO DNase buffer and $1 \mu \mathrm{L}$ TURBO DNase was added to the RNA samples, which were subsequently incubated at $37^{\circ} \mathrm{C}$ for 30 mins. $3 \mu \mathrm{L}$ of DNase Inactivation Reagent was added to the samples and incubated together for 5 mins at room temperature. The samples were centrifuged at $10,000 \times \mathrm{g}$ for 1.5 mins and the supernatant was transferred to a clean microcentrifuge tube.

The SuperScript III Reverse Transcriptase Kit (Invitrogen, Toronto, ON) was used for first-strand cDNA synthesis. RNA samples were denatured according to kit protocol with $250 \mathrm{ng}$ each of oligoDT 12-18 and random hexamer primers (ThermoFisher, Toronto, ON) and brought up to $13 \mu \mathrm{L}$ with sterile water. Reverse transcription was carried out by the addition of $4 \mu \mathrm{L} 5 \mathrm{X}$ First-Strand Buffer, $1 \mu \mathrm{L}$ each of 0.1 M DTT, RNaseOUT Recombinant RNase Inhibitor, and SuperScript III reverse transcriptase (Invitrogen, Toronto, ON). The samples were incubated at $25^{\circ} \mathrm{C}$ for $5 \mathrm{mins}, 50^{\circ} \mathrm{C}$ for 60 mins, and inactivated at $70^{\circ} \mathrm{C}$ for 15 mins. RNA was removed using the addition of $1 \mu \mathrm{L}$ ( 2 units) of Ambion E. coli RNase H (ThermoFisher, Toronto, ON) and incubated at $37^{\circ} \mathrm{C}$ for 20 mins.

\section{RT-qPCR}

TaqMan Gene Expression Master Mix and rat PRL-R primers were purchased from ThermoFisher. $1 \mu \mathrm{L}$ of 20X TaqMan Gene Expression Assay containing primers for PRL-R (Rn01525459_m1) was combined with $10 \mu \mathrm{L}$ of (2X) TaqMan Master Mix, approximately 10.7 ng of SFO cDNA and brought up to $20 \mu \mathrm{L}$ with sterile water and run on a 96-well optical reaction 
plate. The plate was sealed using a MicroAmp Optical Adhesive Film (ThermoFisher, Toronto, ON). RT-qPCR was carried out in duplicates and averaged. Fluorescence was detected using the ABI PRISM 7500 Real-Time PCR System (ThermoFisher, Toronto, ON) over 40 cycles of RTqPCR. The plate was run at $50^{\circ} \mathrm{C}$ for 2 mins, $95^{\circ} \mathrm{C}$ for 10 mins, then cycled at $95^{\circ} \mathrm{C}$ for 15 seconds and $60^{\circ} \mathrm{C}$ for $1 \mathrm{~min}$ for 40 cycles to allow for melting and annealing/extension, respectively. The housekeeping gene, phosphoglycerate kinase (PGK) was used to normalize the PRL-R data. RT-qPCR for PGK primers (Fwd: 5' -CTGTGGGGGTATTTGAATGG-3', Rev: 5'CTTCCAGGAGCTCCAAACTG-3') was performed using Bio-Rad iTaq Universal SYBR Green Supermix. Approximately $5.35 \mathrm{ng}$ of cDNA was added to each well and the 96 -well optical plate was run with the thermocycler set to $95^{\circ} \mathrm{C}$ for $30 \mathrm{~s}, 40$ cycles of $95^{\circ} \mathrm{C}$ for $5 \mathrm{~s}, 60^{\circ} \mathrm{C}$ for $30 \mathrm{~s}$, followed by $72^{\circ} \mathrm{C}$ for 30 s.

\section{Data Analysis}

PRL-R data were collected and analyzed with PE Applied Biosystems sequence detection software and amplification plots (fluorescence relative to an internal reference $\left(\log R_{n}\right)$ ) versus cycle number for PRL-R. An automatic threshold value of fluorescence was set at the exponential phase of the reaction using the software and the cycle number corresponding to the threshold fluorescence $\left(\mathrm{C}_{\mathrm{T}}\right)$ was recorded. $\mathrm{C}_{\mathrm{T}}$ values for all samples were normalized to PGK values (recorded using CFX Manager Software) by calculating $\Delta \mathrm{C}_{\mathrm{T}}$ (values for PGK were subtracted from that of PRL-R). Comparison groups rats $\left(\Delta \Delta \mathrm{C}_{\mathrm{T}}\right)$ were then analyzed using the Pfaffl method (Pfaffl, 2001) and PRL-R mRNA expression relative to the reference group was calculated as the ratio of $2^{-\Delta \Delta C}$ T values. Outliers were removed using the GraphPad Outlier Calculator and statistical analysis was performed using the Student's t-test and one-way ANOVA. Data are presented as mean \pm SEM. 


\section{Electrophysiology}

Current- and voltage- clamp recordings were performed using the whole-cell and perforated-cell methods. The recordings were filtered at $2 \mathrm{kHz}$ using a Multiclamp 700B patchclamp amplifier (Molecular Devices, Sunnyvale, CA). Analog signals were converted to digital at $10 \mathrm{kHz}$ using a Cambridge Electronics Design (CED) Micro1401 interface (Cambridge, UK). Voltage-clamp and current-clamp recordings were displayed using Signal (version 6.01; CED) and Spike2 (version 8.01; CED), respectively.

All recordings used an internal pipette solution containing (in $\mathrm{mM}$ ): 125 potassium gluconate $\left(\mathrm{C}_{6} \mathrm{H}_{11} \mathrm{KO}_{7}\right), 10 \mathrm{KCl}, 2 \mathrm{MgCl}_{2}$ hexahydrate, $10 \mathrm{HEPES}, 1$ EGTA, $0.3 \mathrm{CaCl}_{2}$ dihydrate, and 2 NaATP. KOH was used to balance the solution to $\mathrm{pH}$ 7.3. The solution was filter-sterilized using a $0.22 \mu \mathrm{M}$ filter and the osmolarity was checked to fall within a range of 280-300 mOsm. The internal pipette solution was aliquoted and stored at $-80^{\circ} \mathrm{C}$. Micropipette recording electrodes were made from borosilicate glass (World Precision Instruments, Sarasota, FL) using a P97 Flaming Brown micropipette puller (Sutter Instruments, Novato, CA), such that a filled electrode had a resistance of 2-5 M $\Omega$. The extracellular bath contained a solution of (in $\mathrm{mM}$ ): $140 \mathrm{NaCl}, 5$ $\mathrm{KCl}, 2 \mathrm{CaCl}_{2}$ dihydrate, $1 \mathrm{MgCl}_{2}$ hexahydrate, 5 glucose, 5 mannitol, and $10 \mathrm{HEPES}$. $\mathrm{NaOH}$ was used to $\mathrm{pH}$ balance the solution to 7.3 and osmolarity was checked to fall between $280-300$ mOsm.

\section{Perforated-Cell Recordings}

The antifungal agent, Amphotericin-B (AMPH-B) was used to perforate the cells (SigmaAldrich, Oakville, ON). AMPH-B was prepared daily following previously published protocol (Linley, 2013) which required suspending in $20 \mu \mathrm{L}$ of DMSO per mg and vortexing until dissolved. The solution was stored in aliquots at $-20^{\circ} \mathrm{C}$ for a maximum of 48 hours. Before recording, approximately $10 \mu \mathrm{L}$ of the solution was dissolved in the internal pipette solution by vortex and was used for a maximum of 3 hours before discarding. The recording electrode was 
dipped in internal solution and back-filled with $3 \mu \mathrm{L}$ of internal solution containing AMPH-B. The pipette tip was lowered onto a neuron using a MP-225 micromanipulator (Sutter Instruments, Novato, CA) until contact was made. Slight negative pressure was applied to achieve a G $\Omega$ seal. After a $\mathrm{G} \Omega$ seal was attained, AMPH-B was given time to perforate the membrane until the series resistance stabilized.

\section{Whole-Cell Recordings}

For whole-cell recordings, the recording electrode was filled with $3 \mu \mathrm{L}$ of internal solution. The pipette tip was lowered onto a neuron until contact was made. Whole-cell access was achieved by applying brief negative pressure.

\section{Patch-Clamp Protocol}

Dissociated SFO neurons were perfused using a gravity perfusion system with the $37^{\circ} \mathrm{C}$ external solution at a flow rate of approximately $1 \mathrm{~mL} / \mathrm{min}$. Excess fluid was removed using a vacuum pump. Cells with a fast-activating and -inactivating inward $\mathrm{Na}^{+}$current evoked by a series of voltage steps in voltage-clamp configuration (using Signal2) were classified as neurons. Individual cells which fired $>60 \mathrm{mV}$ action potentials in the current-clamp configuration and displayed a series resistance $<80 \mathrm{~m} \Omega$ were used for analysis of PRL effects on these neurons. The membrane potential $\left(\mathrm{V}_{\mathrm{m}}\right)$ was determined after correction for a calculated $-15.7 \mathrm{mV}$ liquid junction potential to the recorded values. Once a stable baseline was established, approximately 2 $\mathrm{mL}$ of ovine PRL (Sigma, St. Louis, MO) was bath-perfused and perfusion was then switched back to aCSF. The effects of PRL on membrane excitability was determined by comparing the mean $\mathrm{V}_{\mathrm{m}}$ during the $100 \mathrm{~s}$ window before PRL application (baseline) to the mean $\mathrm{V}_{\mathrm{m}}$ in the $100 \mathrm{~s}$ bin with the greatest change in $\mathrm{V}_{\mathrm{m}}$. If the difference in membrane potentials were $\geq 2$ times the $\mathrm{SD}$ of the baseline, the change was classified as a response to PRL. 


\section{Assessment of the Delayed Rectifier $\mathrm{K}^{+}$and Transient $\mathrm{K}^{+}$Currents}

In order to determine the size of the delayed rectifier $\mathrm{K}^{+}$current before and after PRL application, perforated-cell voltage-clamp experiments were performed in the presence of $500 \mathrm{nM}$ tetrodotoxin (TTX) in the external solution to block voltage-gated $\mathrm{Na}^{+}$current. Previous research from our lab suggested blocking $\mathrm{Ca}^{2+}$ conductance does not alter the magnitude or properties of $\mathrm{K}^{+}$currents (Kuksis \& Ferguson, 2015), as such $\mathrm{Ca}^{2+}$ conductance was not blocked in our voltage-clamp experiments. Delayed rectifier $\mathrm{K}^{+}$current was isolated through a voltage-step protocol requiring the neuron to be held at $-75 \mathrm{mV}$ for $100 \mathrm{~ms}$, stepped up to $-40 \mathrm{mV}$ for $100 \mathrm{~ms}$, then for $250 \mathrm{~ms}$, stepped from $-80 \mathrm{mV}$ to $+20 \mathrm{mV}$ in $10 \mathrm{mV}$ increments. This allowed for the inactivation of the transient $\mathrm{K}^{+}$channels prior to the activation of delayed rectifier $\mathrm{K}^{+}$channels. Peak delayed rectifier $\mathrm{K}^{+}$was determined to be the average of the last $50 \mathrm{~ms}$ of the protocol.

The transient $\mathrm{K}^{+}$current was calculated by subtraction of the previously determined delayed rectifier $\mathrm{K}^{+}$current from a new voltage-step protocol in which the neuron was held at -75 $\mathrm{mV}$ for $100 \mathrm{~ms}$ and then stepped from $-80 \mathrm{mV}$ to $+20 \mathrm{mV}$ in $10 \mathrm{mV}, 250 \mathrm{~ms}$ steps. The subtraction of delayed rectifier $\mathrm{K}^{+}$currents from total $\mathrm{K}^{+}$current determined through this protocol thereby isolated the transient $\mathrm{K}^{+}$current. Peak transient $\mathrm{K}^{+}$was determined to be largest current measurement in the subtracted recording. Both protocols were repeated $30 \mathrm{~min}$ after a $2 \mathrm{~min}$ exposure to either $1 \mu \mathrm{M}, 10 \mathrm{nM}$, or $1 \mathrm{nM}$ PRL (data were pooled). Statistical analysis was performed using a paired t-test. 


\section{Results}

\section{PRL-R is expressed in the SFO}

In order to assess the expression of PRL-R, RT-qPCR was performed on homogenized and pooled SFO tissue. We found that PRL-R mRNA is expressed in SFO of juvenile male rats aged 28-35 days (Figure 1; mean $\mathrm{C}_{\mathrm{T}}$ value $30.35 \pm 0.51$ ), as is the mRNA of the housekeeping gene PGK (31.64 \pm 0.40$)$. As circulating PRL levels depend on the sex and sexual maturity of the animal, we next compared PRL-R expression levels before and after puberty and across sexes.

\section{SFO PRL-R expression may occur independently of sexual maturity and sex}

We assessed differences in PRL-R mean $\mathrm{C}_{\mathrm{T}}$ values between juvenile and sexually mature rats, both male and female. No differences in mean $\mathrm{C}_{\mathrm{T}}$ values were observed in juvenile and sexually mature male rats (Figure $\mathbf{2 A} ; 29.17 \pm 0.33$ vs. $28.57 \pm 0.47 ; \mathrm{p}=0.09$ ). We did, however, observe a difference between mean $\mathrm{C}_{\mathrm{T}}$ values in female juvenile and sexually mature rats (Figure 2B; $30.35 \pm 0.51$ vs. $29.39 \pm 0.48 ; \mathrm{p}=0.03$ ). To determine whether the difference in mean $\mathrm{C}_{\mathrm{T}}$ values translated into differences in PRL-R mRNA levels between juvenile and sexually mature female rats, we further calculated relative mRNA expression normalized to PGK using the $2^{-\Delta \Delta C}{ }_{T}$ method. The juvenile PRL-R mRNA expression levels were not significantly different to sexually mature levels when normalized to juvenile expression levels ( $\mathrm{p}=0.87)$. Therefore, PRL- $\mathrm{R}$ expression at the SFO was found to be independent of sexual maturity of the animal. For the sake of clarity, we did not present relative mRNA expression using the $2^{-\Delta \Delta C}$ Tethod which were calculated for all other comparison groups as they were found to be in statistical agreement with mean $\mathrm{C}_{\mathrm{T}}$ analysis and are therefore redundant.

We next compared male and female PRL-R $\mathrm{C}_{\mathrm{T}}$ values in juvenile and sexually mature cohorts. Male and female juvenile rats did not differ in PRL-R mean $\mathrm{C}_{\mathrm{T}}$ values (Figure 3A; 29.17 \pm 0.33 vs. $30.35 \pm 0.51 ; \mathrm{p}=0.41)$. There was also no difference in mean $\mathrm{C}_{\mathrm{T}}$ values between males and females (Figure 3B; $28.57 \pm 0.47$ vs. $29.39 \pm 0.48 ; \mathrm{p}=0.53$ ). In summary, the PCR data 
suggest that PRL-R is expressed at the SFO in both male and female rats and that the expression is stable across sexual maturity and sex.

\section{SFO PRL-R expression may occur independently of estrous cyclicity}

As serum PRL changes dramatically with estrous cyclicity, we investigated PRL-R mRNA expression across the four stages of the estrous cycle (Figure 4). As before, mean $\mathrm{C}_{\mathrm{T}}$ values for PRL-R were not dependent on the stage of the estrous cycle (diestrus: $29.78 \pm 0.83$, proestrus: $29.06 \pm 0.99$, estrus: $29.11 \pm 1.05$, metestrus: $29.68 \pm 0.48$; $\mathrm{p}=0.97$ ). The RT-qPCR experiments suggest that PRL-R expression is stable at the SFO across the estrous cycle in sexually mature female rats.

\section{SFO neurons respond to PRL}

As PRL-R mRNA was equally expressed in both juvenile and sexually mature male and female rats, electrophysiological experiments were performed on juvenile male rats. Responses to PRL application were tested using both whole-cell and perforated-cell recordings in the currentclamp configuration. 67 neurons were patched onto using the whole-cell technique and 24 of these neurons were used to test responsiveness to PRL application. Control neurons in which PRL was not applied showed no deviation from baseline over the course of the recording. The average $\mathrm{V}_{\mathrm{m}}$ was $-71 \pm 2 \mathrm{mV}$. 110 neurons were recorded with perforated-cell techniques, of which 97 were used to test PRL responsiveness. The average $V_{m}$ was $-69 \pm 0.6 \mathrm{mV}$ which was significantly different from whole-cell $\mathrm{V}_{\mathrm{m}}(\mathrm{p}=0.01)$.

To test whether PRL application altered membrane excitability of SFO neurons, 1.5 - 2 $\mathrm{mL}$ of PRL was bath applied to dissociated SFO neurons. As the $\mathrm{V}_{\mathrm{m}}$ was significantly different between whole-cell and perforated-cell recordings, all recordings were analyzed to see if responses were voltage dependent. $\mathrm{V}_{\mathrm{m}}$ was not correlated to the magnitude of depolarizations $\left(\mathrm{R}^{2}=0.25\right)$ or hyperpolarizations to $\mathrm{PRL}\left(\mathrm{R}^{2}=0.03\right)$, therefore further analysis was performed on data pooled from both recording techniques. $40 \%$ of neurons depolarized by $11.26 \pm 1.72 \mathrm{mV}$ and 
14\% hyperpolarized by $-6.65 \pm 1.39 \mathrm{mV}$ to $1 \mu \mathrm{M}$ PRL application (Figure 5). The remaining $46 \%$ of neurons did not respond to PRL at this concentration. Taken together, responses to $1 \mu \mathrm{M}$ PRL suggest two subpopulations of SFO neurons which are either inhibited by or excited by PRL.

Magnitude and proportion of PRL responses did not differ between whole- and perforated-cell recordings at the $1 \mu \mathrm{M}$ concentration ( $\mathrm{p}=0.41$ for depolarizations, $\mathrm{p}=0.35$ for hyperpolarizations). However, whole-cell and perforated-cell recordings did differ in length of responses to PRL. Only 2 neurons out of 24 completely recovered to baseline following the response to PRL application and reperfusion of external solution in whole-cell configuration (depolarization recovered after 20 minutes and hyperpolarization recovered after 15 mins). In perforated-cell, 27 of 48 depolarizations were followed by a complete recovery (average length of response was 47 mins). 15 of 18 hyperpolarizations recovered to baseline (average length was 68 mins). Some responses to PRL did not recover to baseline during the recording; we recorded a depolarization of over 4.9 hours and a hyperpolarization of over 3.3 hours after PRL application, suggesting PRL signaling at the SFO is robust and long-lasting.

\section{PRL responses were not found to be dependent on PRL concentration}

As physiological concentrations of serum PRL translate to the high $\mathrm{pM}$ - low nM range, magnitude and proportion of PRL responses were compared across the range of $10 \mathrm{pM}$ to $1 \mu \mathrm{M}$ (Figure 6). Data were pooled from both whole- and perforated-cell techniques. The proportion of depolarizations and hyperpolarizations did not significantly change within the $10 \mathrm{pM}$ to $1 \mu \mathrm{M}$ range $\left(X^{2}, \mathrm{p}=0.19\right)$. One-way ANOVAs were used to analyze differences in magnitudes of depolarizations and hyperpolarizations across the same concentration range. The magnitude of both depolarizations and hyperpolarizations did not significantly differ within the range of $10 \mathrm{pM}$ to $1 \mu \mathrm{M}$ ( $\mathrm{p}=0.53$ and 0.58 , respectively), suggesting that responses may be concentrationindependent. In summary, the current-clamp recordings collected with both whole- and 
perforated-cell techniques revealed PRL-responsive neurons which either depolarized or hyperpolarized to PRL application and some of these responses lasted on the scale of hours. Furthermore, we observed that magnitude and proportion of responses to PRL were not dependent on concentration in the $10 \mathrm{pM}$ to $1 \mu \mathrm{M}$ range.

\section{PRL responses involve selective reduction of transient $\mathrm{K}^{+}$current}

Perforated-cell current-clamp experiments were both preceded and followed by voltageclamp recordings to confirm that the cell recorded from, was a neuron and that access into the cell was not compromised over the course of the recording. Interestingly, some voltage-clamp recordings following PRL application in the current-clamp configuration suggested a reduction in transient $\mathrm{K}^{+}$current following PRL application (Figure 7). This reduction was observed mostly in cells that depolarized to PRL, and in some cases even after recovery in membrane potential was observed. Further perforated-cell voltage-clamp experiments were performed to confirm selective reduction of transient $\mathrm{K}^{+}$current after PRL application (Figure 8).

In order to elucidate the potential role of $\mathrm{K}^{+}$conductance in responses to PRL, voltageclamp recordings were performed on dissociated SFO neurons in the presence of $500 \mathrm{nM}$ TTX to eliminate $\mathrm{Na}^{+}$conductance. Recordings were taken before and 30 min after $2 \mathrm{~mL}$ PRL was bathapplied. The representative current-voltage (I-V) relationship for cells that respond to PRL demonstrate a reduction in the transient $\mathrm{K}^{+}$current at depolarized potentials. This difference is not observed in the IV plot of the delayed-rectifier $\mathrm{K}^{+}$current in the same cell. In order to quantify this difference, we compared the $0 \mathrm{mV}$ step of all responsive cells. We observed a significant reduction in the transient $\mathrm{K}^{+}$current to $39 \%$ of the size of the current before PRL application $\left(\mathrm{p}=0.02, \mathrm{n}=6\right.$ of 9). The reduction in $\mathrm{K}^{+}$current is specific to transient $\mathrm{K}^{+}$channels as delayedrectifier $\mathrm{K}^{+}$current is not significantly different after PRL application $(\mathrm{p}=0.32)$ at the $0 \mathrm{mV}$ step. We therefore conclude that PRL selectively reduces transient $\mathrm{K}^{+}$current in a subpopulation of SFO neurons. 


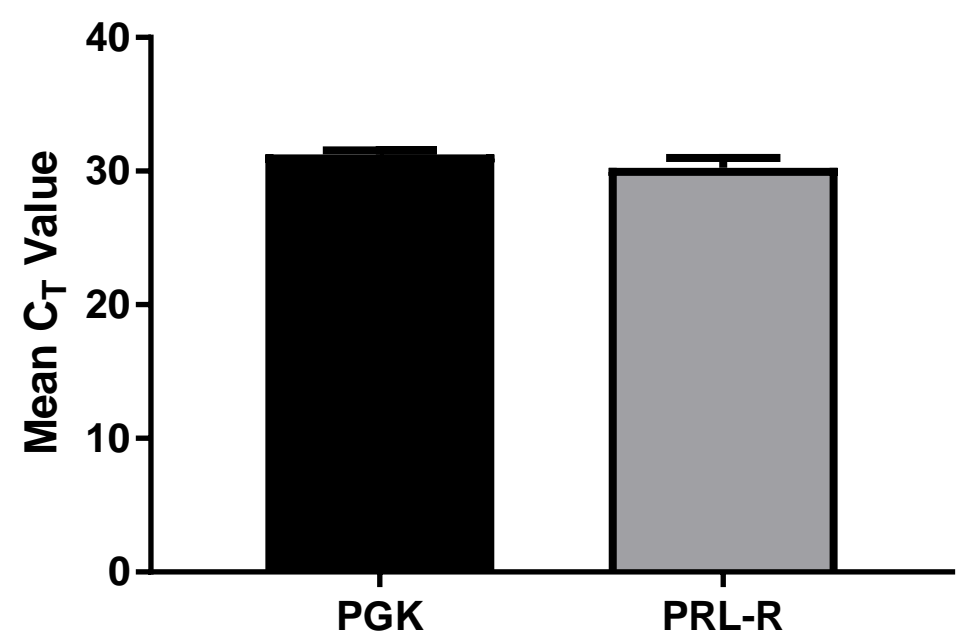

Figure 1: PRL-R and PGK are expressed in the SFO

Mean $C_{T}$ values for PRL-R and housekeeping gene PGK mRNA in the SFO of juvenile male rats $(\mathrm{n}=5)$. Error bars represent SEM.

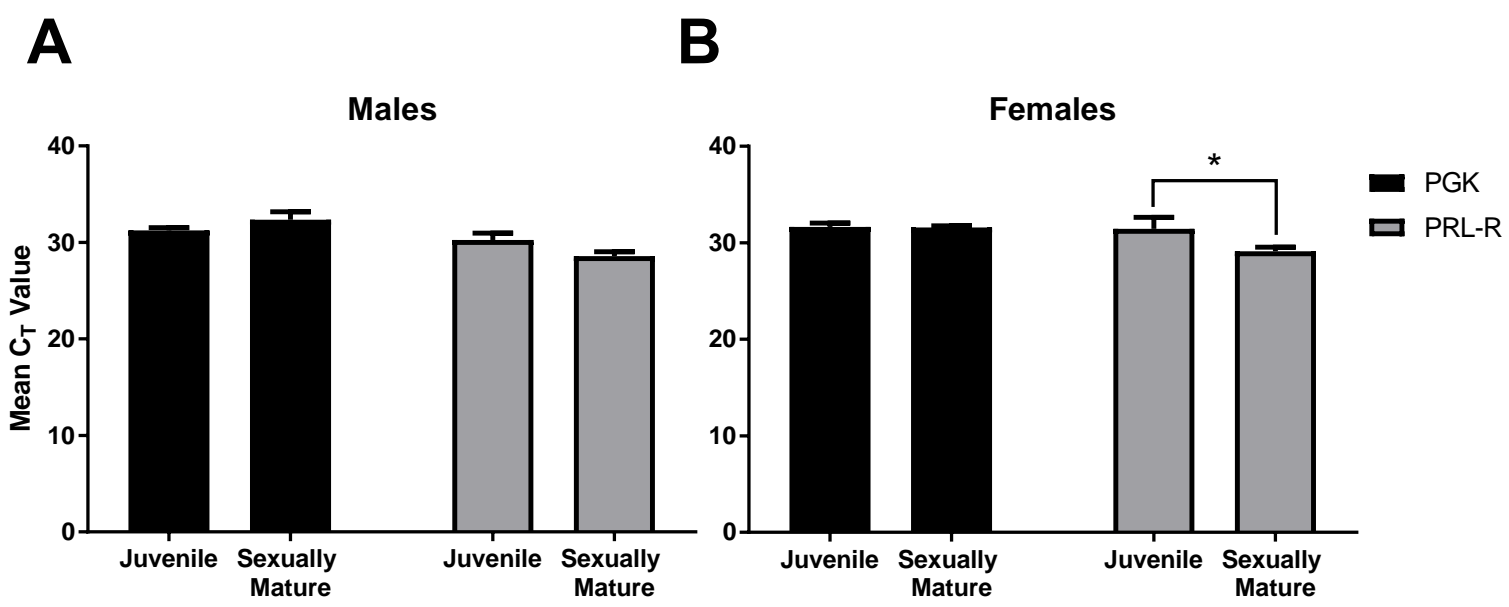

Figure 2: PRL-R and PGK are expressed in the SFO and may be independent of sexual maturity

Mean $\mathrm{C}_{\mathrm{T}}$ values for PRL-R and housekeeping gene PGK mRNA in the SFO of $\mathbf{A}$ ) male and $\mathbf{B}$ ) female rats. No significant differences were observed in male PRL-R mean $C_{T}$ values between juvenile $(n=5)$ and sexually mature $(n=5)$ comparison groups $(p=0.09)$. Female PRL-R mean $C_{T}$ values were significantly different between juveniles $(n=5)$ and sexually mature $(n=19)$ comparison groups ( $\mathrm{p}=0.03$ ). Post-hoc $2^{-\Delta \Delta \mathrm{C}} \mathrm{T}$ analysis found no significant difference in relative expression levels for PRL-R in females ( $\mathrm{p}=0.87$ ). Error bars represent SEM. 
Juveniles

B
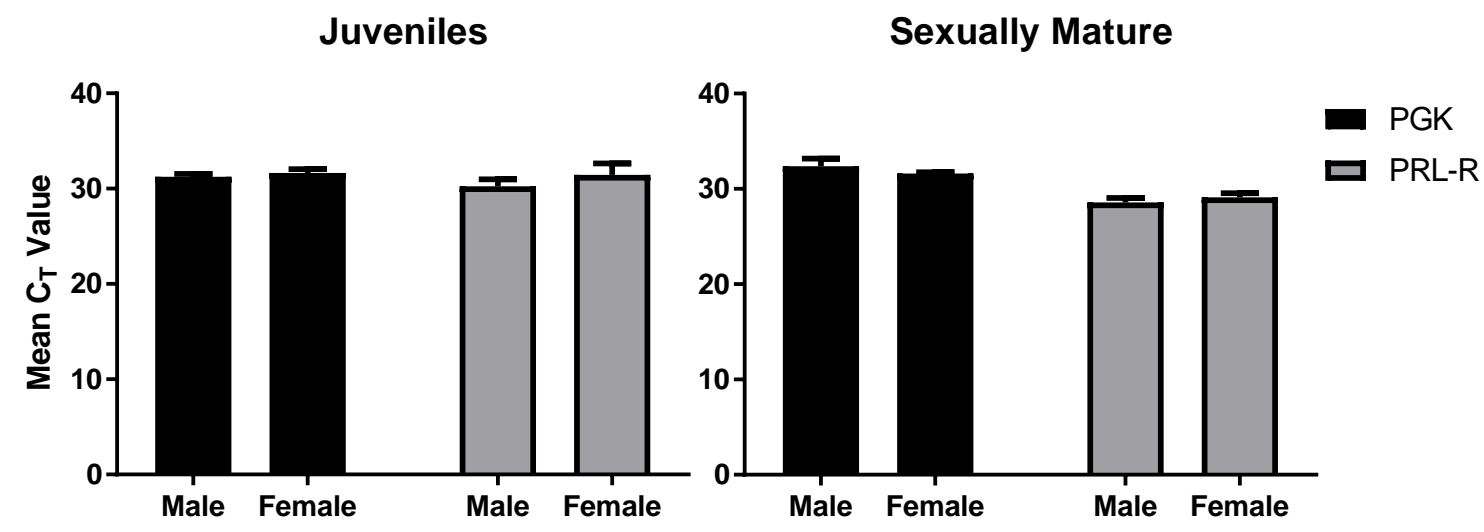

Figure 3: PRL-R and PGK are expressed in the SFO and may be independent of sex

Mean $\mathrm{C}_{\mathrm{T}}$ values for PRL-R and housekeeping gene PGK mRNA in the SFO of $\mathbf{A}$ ) juvenile and $\mathbf{B}$ ) sexually mature rats. No significant difference was observed in juvenile PRL-R mean $C_{T}$ values between male $(n=5)$ and female $(n=5)$ comparison groups $(\mathrm{p}=0.41)$. No significant difference was observed between sexually mature male $(n=5)$ and female $(n=19)$ comparison groups $(p=0.53)$. Data presented are taken from Figure 2. Error bars represent SEM.

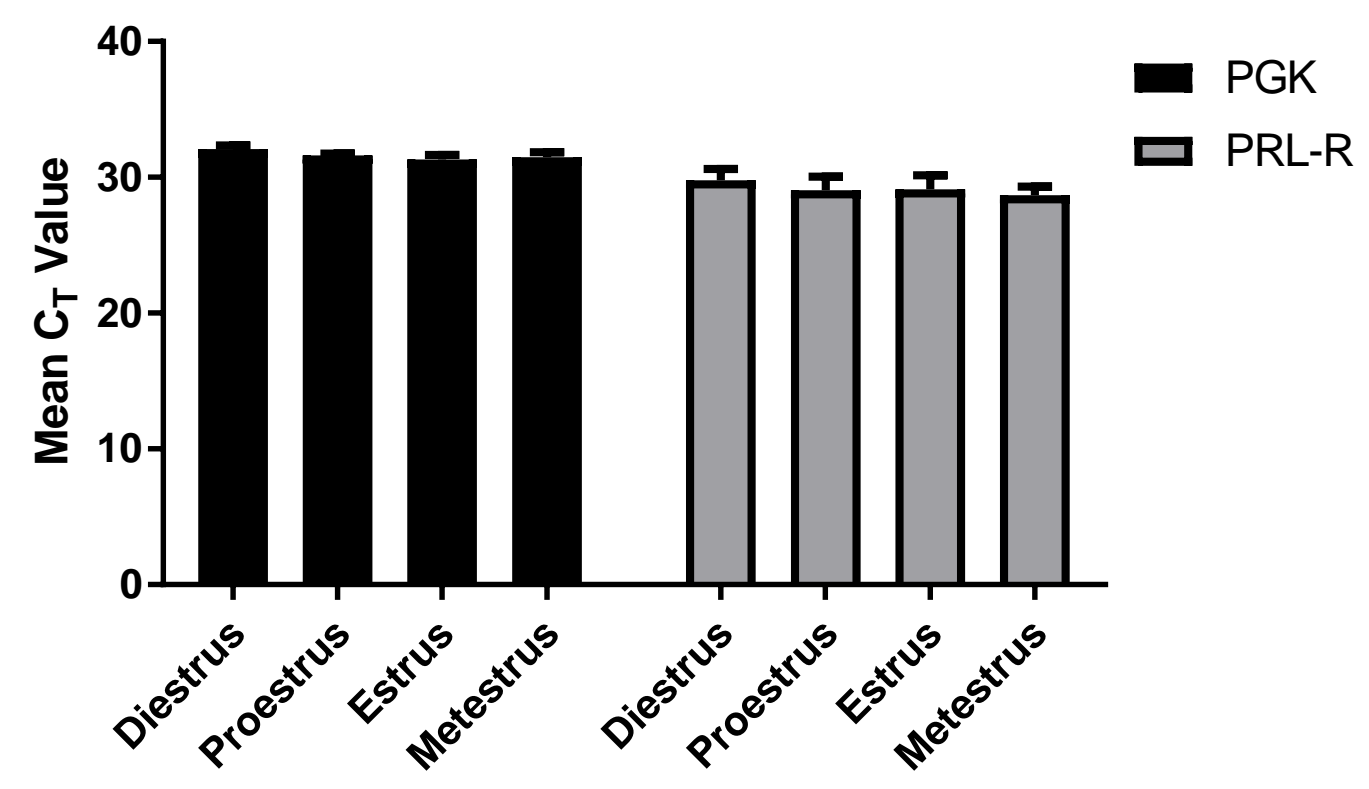

Figure 4: PRL-R and PGK are expressed in the SFO and may be independent of estrous cyclicity

Mean $\mathrm{C}_{\mathrm{T}}$ values for PRL-R and housekeeping gene PGK mRNA in the SFO across the estrous cycle. No significant differences were observed between diestrus $(n=4)$, proestrus $(n=5)$, estrus $(n=5)$, and metestrus $(n=5)$ mean $C_{T}$ values $(p=0.97)$. Error bars represent SEM. 

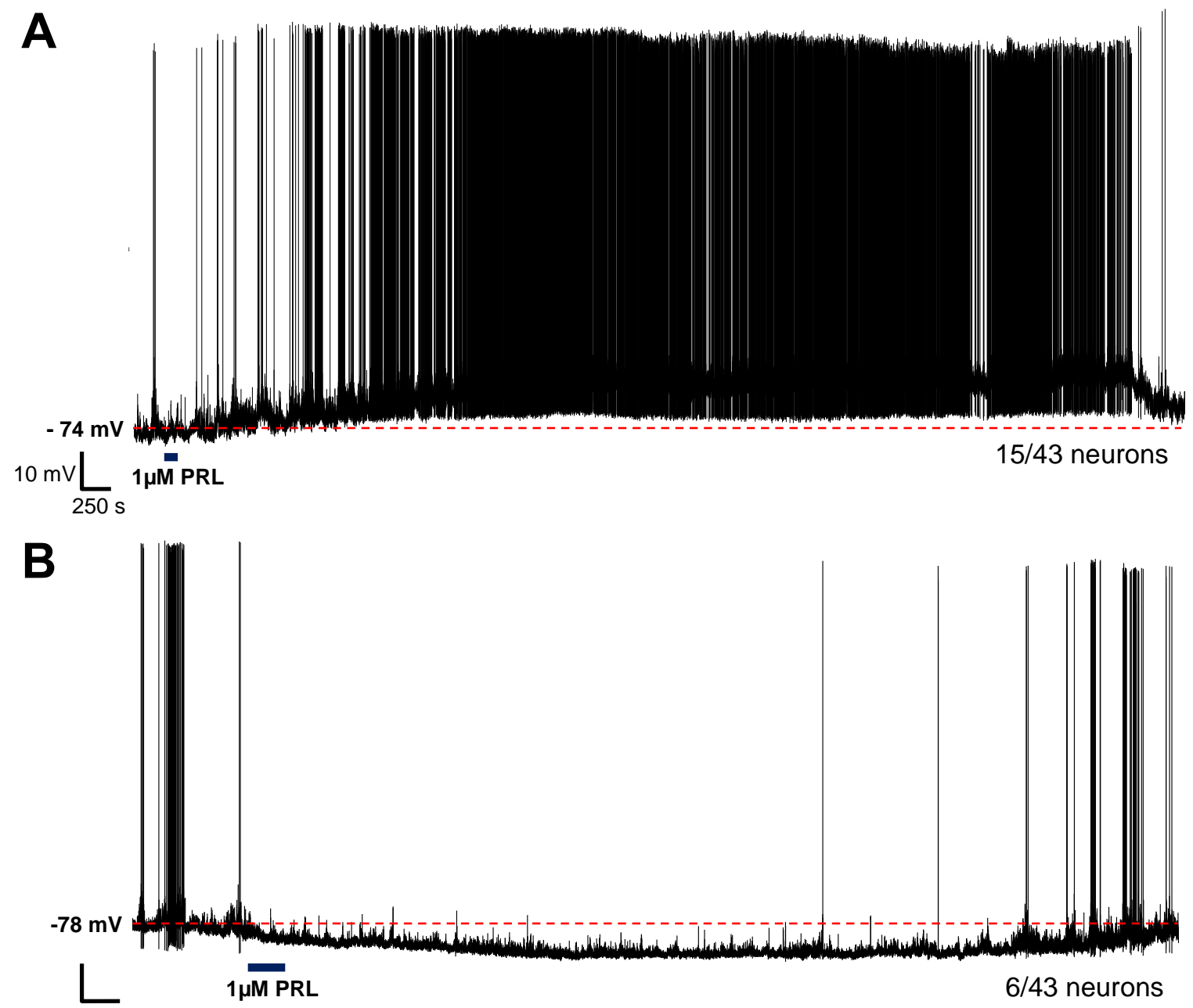

Figure 5: PRL affects membrane excitability of SFO neurons

Representative current-clamp recordings from 2 SFO neurons illustrating subpopulations of neurons which A) depolarize and B) hyperpolarize to $1 \mu \mathrm{M}$ PRL application. Time and duration of application is indicated by the blue bar under each current trace. 
A

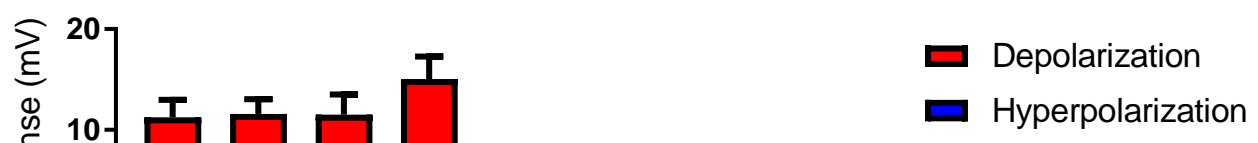

B

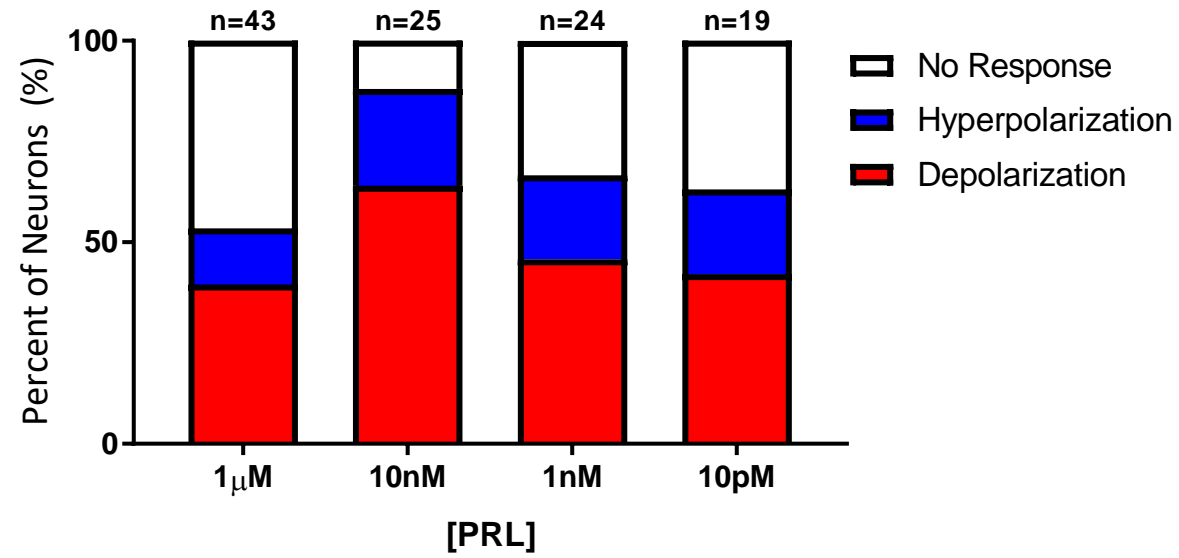

Figure 6: Responses to PRL may occur independently of PRL concentration

Within the range of $1 \mu \mathrm{M}$ to $10 \mathrm{pM}$ PRL, A) magnitude of depolarizations $(\mathrm{p}=0.53)$ and hyperpolarizations $(\mathrm{p}=0.58)$ were not significantly different between concentrations and $\mathbf{B})$ proportion of responses were not significantly different between concentrations $\left(X^{2}, \mathrm{p}=0.19\right)$. 


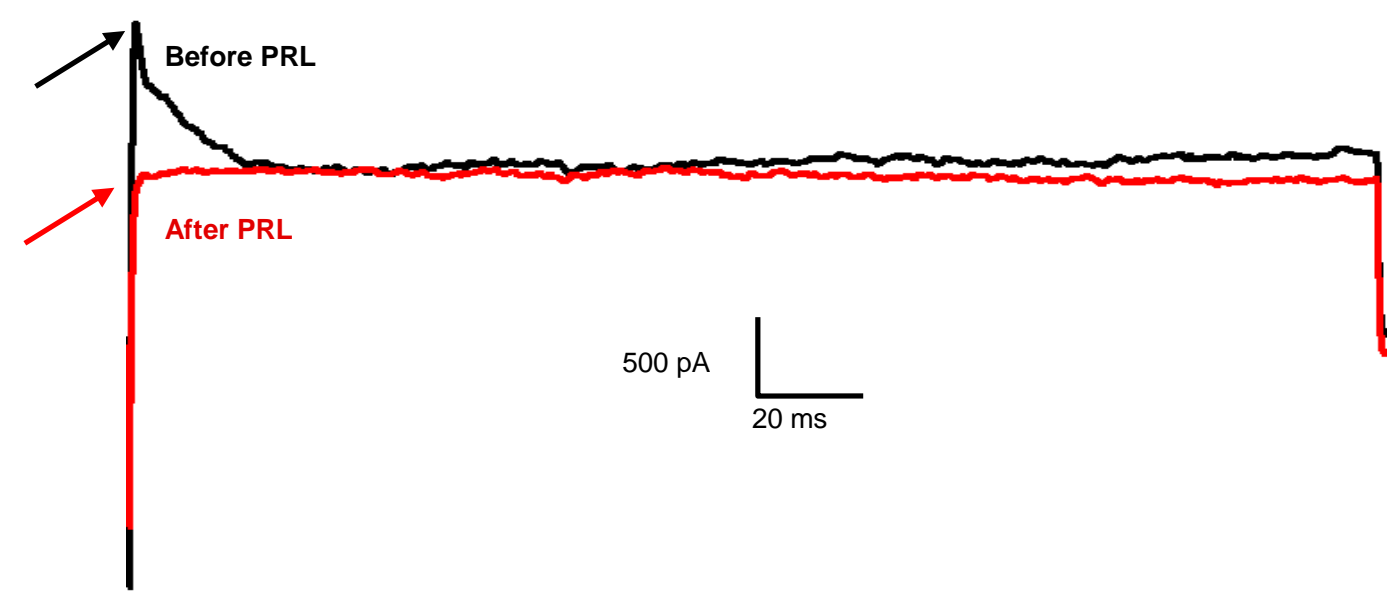

Figure 7: PRL responses in current-clamp are accompanied by reduction of transient $\mathrm{K}^{+}$ current in voltage-clamp

Representative voltage-clamp recording of a cell which responded to PRL in current-clamp, before and after $2 \mathrm{~mL}$ of $1 \mu \mathrm{M}$ PRL was applied. Arrows represent peak transient $\mathrm{K}^{+}$current at the $20 \mathrm{mV}$ step. 

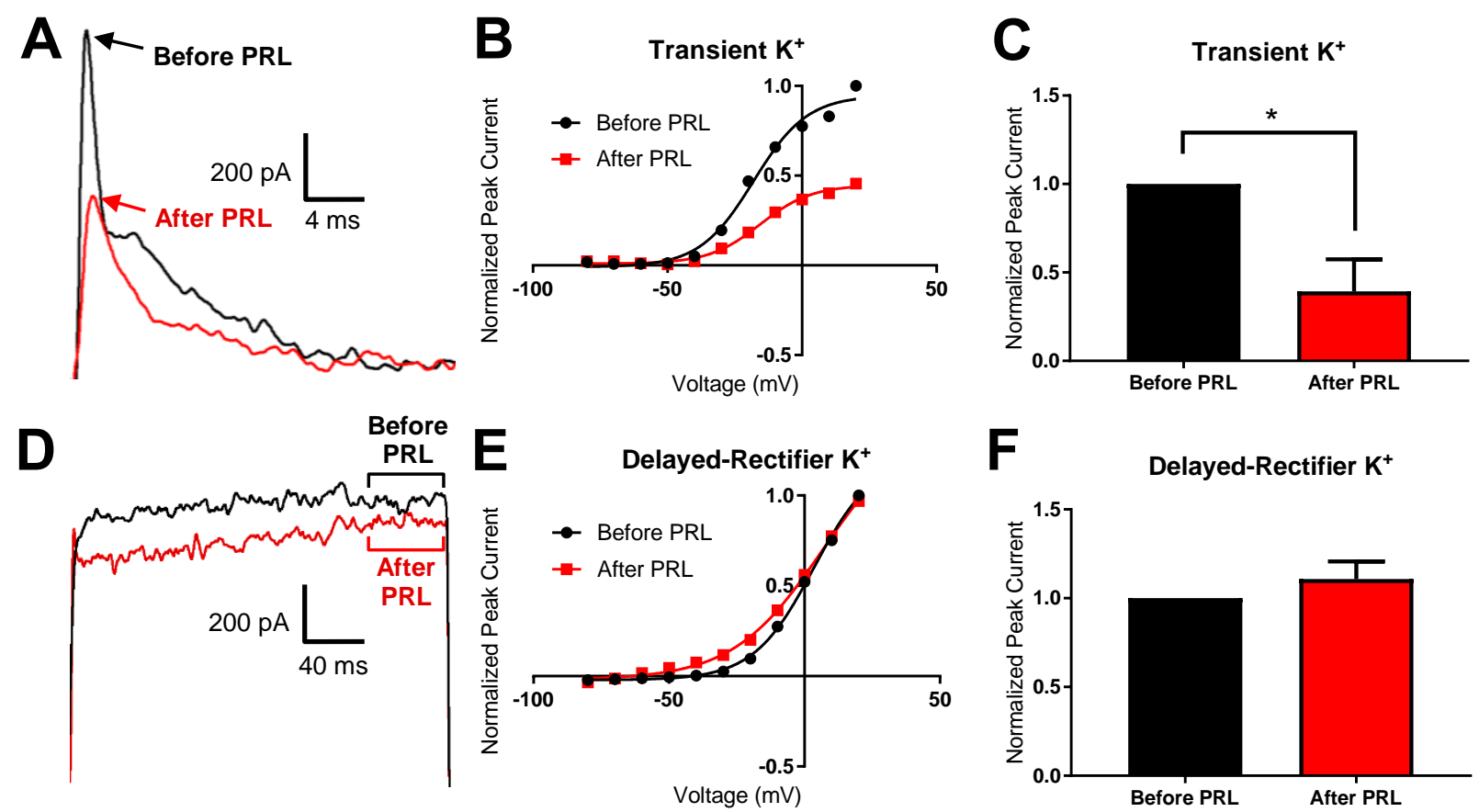

Figure 8: PRL responses in voltage-clamp involve the selective reduction of transient $\mathrm{K}^{+}$current (A) and (D) Representative voltage-clamp recordings of TTX-isolated $\mathrm{K}^{+}$current in PRL-responsive SFO neurons ( $\mathrm{n}=6$ of 9) at the $0 \mathrm{mV}$ step. (A) Peak transient $\mathrm{K}^{+}$current (arrow) is significantly reduced 30 mins after $2 \mathrm{~mL}$ PRL application ( $\mathrm{p}=0.02$ ) while (D) peak delayed-rectifier $\mathrm{K}^{+}$current (bracket) is not significantly altered $(\mathrm{p}=0.32)$. (B) and (E) Representative I-V relationships of peak transient and delayed-rectifier $\mathrm{K}^{+}$ currents, respectively, 30 mins after PRL application; normalized to peak current before application. Peak transient $\mathrm{K}^{+}$current is reduced at depolarized voltages after PRL application while delayed-rectifier $\mathrm{K}^{+} \mathrm{I}-\mathrm{V}$ relationship remains unchanged after PRL application. (C) and (F) Bar graphs summarizing mean peak transient and delayed-rectifier $\mathrm{K}^{+}$currents, respectively, 30 mins after PRL application relative to size of currents before application at the $0 \mathrm{mV}$ step. 


\section{Discussion}

Our study presents novel evidence of PRL signaling in the SFO in showing that the receptor for PRL is not only expressed in the SFO, but it is expressed independently of sex, sexual maturity, and estrous cyclicity of the animal. In addition, PRL directly excites and inhibits two different subpopulations of dissociated SFO neurons, and these responses involve a reduction of the transient $\mathrm{K}^{+}$current. To our knowledge, we are the first to characterize the influence of PRL on the membrane excitability of SFO neurons as well as compare PRL-R expression at the SFO.

\section{RT-qPCR Experiments}

Our initial PCR studies confirmed the expression of PRL-R in SFO. While these experiments quantified mRNA expression of the PRL-R and housekeeping gene PGK, we used these values as a proxy for PRL-R protein expression. Augustine et al. (2003) also used RT-qPCR to compare PRL-R in the maternal rat brain. In the same study, immunohistochemistry was performed; the relative intensity of PRL-R immunofluorescence was similar to relative expression of PRL-R mRNA suggesting that mRNA expression identified using RT-qPCR is an accurate measure of post-translational PRL-R expression (Augustine et al., 2003).

We used this modified PCR to compare the expression of PRL-R across sexual maturity and sex. As serum PRL increases after puberty (Döhler \& Wuttke, 1975) and as PRL is able to regulate its own receptor expression (Brandebourg, Bown, \& Ben-Jonathan, 2007), we expected sexually mature, 3-month-old rats to have higher PRL-R mRNA expression than 28-35 day old juvenile rats. The mean $C_{T}$ values showed that this held true for females but not males, suggesting PRL-R expression in males occurs independently of sexual maturity. Given that differences in $C_{T}$ values do not necessarily translate into differences in relative expression of PRL-R, we compared relative expression of PRL-R across sexual maturity in females using the $2^{-\Delta \Delta C}{ }_{T}$ method which normalized PRL-R mRNA levels to that of PGK and then compared PRL-R mRNA levels 
between juvenile and sexually mature female rats. No significant differences in PRL-R expression were found across sexual maturity in females. The $2^{-\Delta \Delta C}$ Tethod was also used to compare expression in all other comparison groups tested and were in statistical agreement with the $\mathrm{C}_{\mathrm{T}}$ value comparisons.

Next, we compared the SFO PRL-R expression between males and females and found no differences in mean $\mathrm{C}_{\mathrm{T}}$ values of PRL-R at the SFO of males vs females regardless of the sexual maturity of the animal. Additionally, in sexually mature female rats, circulating PRL levels change across the stages of the estrous cycle (Silveyra, Catalano, Lux-Lantos, \& Libertun, 2007). We therefore characterized PRL-R expression in the SFO across the estrous cycle and again found that PRL-R expression were not significantly different across the four stages of the estrous cycle.

The stability in PRL-R expression in the SFO across sexual maturity, sex, and estrous cyclicity suggests that the function of PRL-R is conserved in these animals, or, at the very least, the PRL-R operates to the same extent in the different physiological states we compared. In order to strengthen our understanding of PRL-R function in the SFO, we next determined the effects of PRL application on SFO neurons.

\section{Electrophysiological Experiments}

As the results of the RT-qPCR experiments suggest PRL-R expression is conserved across sex and sexual maturity, we continued our experiments using juvenile male rats to investigate the direct effects of PRL application on dissociated SFO neurons. We chose this model to record from as it offers the advantage of direct access to single SFO neurons without the potential confounds of synaptic input from other neurons, communication with glial cells and endothelium, as well as physical restriction from connective tissue (Gordon, Amini, \& White, 2013). More specifically, the SFO lies adjacent to the choroid plexus and may therefore interact with cells of the choroid plexus which densely express PRL-R (Di Carlo, Muccioli, Papotti, \& 
Bussolati, 1992). Dissociation of the SFO in previous experiments have preserved the function and morphology of the SFO; dissociation did not alter the responsiveness to ANG in both proportion and magnitude of response (Cancelliere \& Ferguson, 2017; A. V. Ferguson et al., 1997).

\section{Whole- and Perforated-Cell Recordings}

The application of PRL in whole- and perforated-cell current-clamp recordings identified two differentially responsive subpopulations of SFO neurons. Two-thirds of SFO neurons respond to PRL within the range of $10 \mathrm{pM}$ to $1 \mu \mathrm{M} ; 47 \%$ of all SFO neurons depolarized and $19 \%$ hyperpolarized in response to PRL ( $\mathrm{n}=111$ total). While the data from whole- and perforated-cell recordings were pooled, one aspect of our recordings that differed between the two methods of patch-clamping was the time period for which the recordings were maintained. Seals achieved through perforated-cell are far more stable than seals achieved through whole-cell methods. This is likely because the integrity of the cell membrane is not compromised in the process of accessing the internal milieu. Moreover, the large molecules such as signaling proteins from the internal milieu are unable to mix with the internal solution of the pipette, thereby allowing the cell to maintain its cytoplasmic contents for a longer period of time. Through perforated-patch, we were able to achieve recordings of up to 5 hours, which allowed us to observe the long-lasting, robust nature of PRL responses. Some responses did not recover over the course of the recording, depolarizations of up to 5 hours and hyperpolarizations of over 3 hours were observed at various concentrations. This suggests that the response to PRL in some cells last on the scale of hours. Given PRL's ability to modulate transcription, it could be that the response was potentiated by means of integrating newly translated ion channels into the membrane. To test this theory, experiments in which PRL is applied in the presence of protein synthesis inhibitors would have to be performed. The time of onset of the PRL response occurs 
more rapidly than would be required for the synthesis of new ion channels. It is therefore likely that PRL induces short- and long-term changes in SFO neurons.

Since the physiological PRL levels are in the $\mathrm{pM}$ to $\mathrm{nM}$ range (as reviewed in Patil et al., 2014), we next determined if PRL responses were dependent on PRL concentration. Proportion and magnitude analyses were performed within the $1 \mu \mathrm{M}$ to $10 \mathrm{pM}$ range. Neither the proportion nor the magnitude of responses to PRL were significantly different; further investigation is required to determine if the biological activity of PRL in the SFO occurs independently of concentration. However, species-specific binding affinity may also account for the responses across the wide range of concentrations tested. The $\mathrm{EC}_{50}$ of PRL was demonstrated to be speciesspecific, with ovine PRL binding more strongly than rat PRL for the human PRL-R (Ocłon et al., 2017). Given the novel aspect of our study, we chose to use ovine PRL for its potency. Therefore, it is possible that the range of $1 \mu \mathrm{M}$ to $10 \mathrm{pM}$ falls at the top of the concentration-response curve. Further experiments would have to be performed to identify if a clearer concentration response curve is observed in response to rat PRL.

We next performed voltage-clamp experiments to elucidate ion channels modulated by PRL in SFO neurons. Our preliminary voltage-clamp experiments performed before and after our current-clamp recordings demonstrated a dramatic reduction in transient $\mathrm{K}^{+}$current in some SFO neurons after PRL application. Previously, PRL has been shown to inhibit BK-type $\mathrm{K}^{+}$channels and voltage-independent $\mathrm{Ca}^{2+}$ channels such as TRP channels (Lyons et al., 2012). To our knowledge, no studies have identified transient $\mathrm{K}^{+}$channels as a potential target of PRL action. We isolated $\mathrm{K}^{+}$current in the presence of $500 \mathrm{nM}$ TTX and examined the effects of PRL on currents elicited using voltage-clamp protocols which isolated delayed-rectifier and transient $\mathrm{K}^{+}$ currents. 30 minutes after $2 \mathrm{~mL}$ PRL application, transient $\mathrm{K}^{+}$currents were significantly reduced while delayed-rectifier $\mathrm{K}^{+}$currents were unaffected. $67 \%$ of neurons tested showed a reduction in transient $\mathrm{K}^{+}$, however, more experiments would have to be performed in order to correlate type of 
response (depolarization vs hyperpolarization) to changes in transient $\mathrm{K}^{+}$currents. The changes in transient $\mathrm{K}^{+}$conductance reached a plateau and did not recover during the duration of our recordings (average length was 52 mins), which agrees with our observation of robust and longlasting changes in membrane excitability following PRL application. While we did not look at other ion channels, $\mathrm{Ca}^{2+}$-dependent $\mathrm{K}^{+}$and TRP channel activity may also be mediated by PRL. Changes in intracellular $\mathrm{Ca}^{2+}$ levels could be related to both of these ionic conductances; experiments on cultured hippocampal neurons showed that PRL application increased intracellular $\mathrm{Ca}^{2+}$ levels (Rivero-Segura et al., 2017). Further experiments are necessary to elucidate the involvement of these and other ion channels in PRL signaling at the SFO.

\section{PRL-R Isoforms}

We should emphasize that total PRL-R mRNA was probed for in our experiments; however, PRL-R exists in three isoforms in the rat: short, long, and the less-expressed intermediate form. Thus, while differences in receptor expression were not found when analyzing total PRL-R mRNA levels, it remains possible that the isoforms of PRL-R could still be differentially expressed. Previous experiments have characterized many regions of the CNS as dually expressing long and short isoforms of the PRL-R, including the AVPV, SON, and ARC. However, regions within the forebrain which preferentially express one form over another include the MnPO, PVN, and the choroid plexus (Patil et al., 2014). Further analysis of the SFO is therefore required to elucidate the relative distribution of long and short isoforms of the PRL-R.

We identified two types of responses to PRL in SFO neurons: depolarizations and hyperpolarizations. These responses could be mediated by differences in isoforms. The long form of the PRL-R can signal through the JAK2/STAT5, MAPK, and PI3K/AKT pathways while the short isoform of the receptor cannot signal through the JAK2/STAT5 pathway. The short form of the receptor, through a PI3K-dependent pathway, enhanced TRP channel activity in trigeminal sensory neurons (Belugin et al., 2013). $\mathrm{Ca}^{2+}$-dependent $\mathrm{K}^{+}$channel activity was altered through 
JAK2 in breast cancer cells (Faouzi, Chopin, Ahidouch, \& Ouadid-Ahidouch, 2010). We identified the inhibition of transient $\mathrm{K}^{+}$following PRL application, however, further experiments would have to be performed to confirm whether this inhibition contributes to the mechanism of PRL-induced depolarization of SFO neurons and to identify whether PRL responses are isoformspecific.

\section{Function of PRL in the SFO}

\section{Osmoregulation}

The functional implication of our data remains to be determined. Studies of PRL action in fish have implicated PRL in osmoregulation and ion uptake (Breves et al., 2016; Shu et al., 2016; Watanabe et al., 2016), and these studies have given insight into PRL's role in osmoregulation, especially during pregnancy, lactation, and fetal development (Bern, 1975). It is possible that PRL serves as an osmoregulatory signal in the SFO, a region of the brain that is known to control fluid balance, and that the hydromineral demands during pregnancy and lactation potentiate the PRL signaling through the SFO already present in males and females. Furthermore, our results show that PRL inhibits the transient $\mathrm{K}^{+}$current in SFO neurons, which is one of the mechanisms by which angiotensin II (ANG) modulates membrane excitability in SFO neurons (Ferguson \& $\mathrm{Li}, 1996)$. This suggests a common mechanism through which these two peptides may modulate the excitability of SFO neurons that are responsible for osmoregulation. In support of this argument, intravenous PRL injection into male and female rats potentiated the effects of ANG on water intake and fluid retention (Kaufman, 1981). In the same study, PRL injection alone in animals with decreased extracellular fluid space led to an increased net water gain when compared to vehicle-injected animals. Therefore, neurons which respond to PRL may also be ANG-responsive, and these neurons are osmoregulatory in both males and females. 


\section{Metabolism}

PRL may work with another hormone, leptin, to maintain energy and fluid homeostasis. While leptin preferentially signals through STAT3 and PRL through STAT5, both cytokine receptors use similar intracellular signaling proteins. In the hypothalamus, populations of neurons in the medial preoptic area, retrochiasmatic area, and the NTS labelled for the leptin receptor, coexpressed the phosphorylated form of STAT5 (pSTAT5), indicating PRL is signaling through these neurons. The cross-talk between leptin and PRL is observed both in nulliparous and pregnant animals and as many as 50\% of leptin neurons co-express pSTAT5 (Nagaishi et al., 2014). Moreover, leptin's effects in the SFO are also implicated in fluid homeostasis as leptin receptor knockout in the SFO abolishes leptin-induced increases in renal sympathetic nerve activity (Young, Morgan, Butler, Mark, \& Davisson, 2013). PRL signaling may potentiate the activity of leptin in increasing blood pressure and altering metabolism. Therefore, PRL may contribute to fluid and energy balance as well as reproductive function through actions at the SFO.

\section{Reproduction}

Perhaps the most logical role for the SFO in PRL signaling is that this CVO represents a specific CNS entry point at which circulating PRL may directly access the brain without the need to cross the $\mathrm{BBB}$ and thus influence brain regions which are critical for the diverse autonomic functions played by this peptide. Different hypothalamic nuclei inside of the BBB have been shown to be differentially sensitive to serum PRL. PRL-responsive cells in the ARC and parvocellular oxytocin neurons in the PVN are more sensitive to low concentrations of PRL than other PRL-responsive neurons in the PVN, SON, and rostral preoptic area (Sapsford, Kokay, Ostberg, Bridges, \& Grattan, 2012). Coincidentally, the SFO provides input into neurons of the ARC and provides region-specific input into the PVN (Kawano \& Masuko, 2010; Rosas-Arellano et al., 1996). The main control of PRL secretion comes from the negative feedback onto anterior 
pituitary lactotrophs from TIDA neurons residing in the ARC. The SFO could therefore act to increase the sensitivity of ARC to PRL, as signaling from the SFO to the ARC is more temporally accurate than if the ARC were solely dependent on PRL entry into the cerebrospinal fluid through receptor-mediated endocytosis at the choroid plexus. Conversely, the SFO could function to decrease the sensitivity of the ARC nucleus to increase serum PRL levels, as would be observed in late gestation and lactation (Biswas \& Rodeck, 1976).

Another potential target for PRL-responsive SFO neurons may be the kisspeptin neurons in the ARC and AVPV which are required for regulation of estrous cyclicity. AVPV kisspeptin neurons provide positive feedback onto GnRH neurons, which ultimately are responsible for the LH surge. ARC kisspeptin neurons provide negative feedback onto GnRH. Over- or undersecretion of PRL into the bloodstream both can result in disruption of fertility, and thus it is possible that the SFO serves as an integrative site for PRL action that project to kisspeptin neurons ultimately governing gonadotropin release. This hypothesis is corroborated by studies in which disruption of PRL signaling and SFO lesioning both lead to irregular or disrupted estrous cyclicity (Horseman et al., 1997; Limonta et al., 1981). Moreover, the AVPV contains subpopulations of neurons that are indirectly PRL-responsive; these neurons do not respond to PRL in the presence of TTX (Silveira et al., 2017). This positions the SFO as a potential PRLresponsive efferent input into the AVPV.

The reproductive hormone oxytocin works in tandem with PRL to induce lactation, and as such, provides another potential mechanism through which PRL functions. The PVN contains subpopulations of neurons that hyperpolarize to PRL, both oxytocinergic and non-oxytocinergic (Sirzen-Zelenskaya et al., 2011). These neurons may also be indirectly PRL-responsive, however appropriate experiments to determine whether those PRL responses are direct or indirect are lacking. A different study on CRH neurons in the PVN demonstrates that CRH neurons which are PRL-responsive, do not coexpress the marker for PRL activation, pSTAT5 (Gustafson, Kokay, 
Sapsford, Bunn, \& Grattan, 2017). It is therefore possible that the SFO projections to the PVN increase the sensitivity of PVN oxytocin and CRH neurons, or may directly signal to these neurons to carry out PRL functions, which includes suppression of the stress response. During pregnancy, higher cortisol levels are accompanied with attenuated cortisol-stress responses. This response has implicated both oxytocin and CRH neuron activity (Neumann et al., 1998). Both oxytocin and PRL administration attenuates cortisol increases following acute stress, and this response was observed in lactating and non-lactating animals (Cook, 1997). More recently, it has been shown that ICV infusion of PRL suppresses the stress axis through the activity of both CRH and oxytocin neurons (Torner, Toschi, Nava, Clapp, \& Neumann, 2002)0. SFO activation by PRL could therefore mediate reproductive influences on the stress axis.

\section{Summary of PRL Function}

It is unlikely that PRL signaling through the SFO serves a singular function. The functions of PRL suggested may be the very same ones potentiated during pregnancy and lactation; preparing the body to lose fluid and electrolytes to the fetus and through lactation, increasing the availability of nutrients to the mother, suppressing the stress response in late-stage pregnancy, and modulating gonadotropin release. Further experiments are required to identify the projections of PRL-responsive SFO neurons, the co-expression of receptors for other hormones, and characterize PRL-R expression and function at the SFO during pregnancy and lactation. Our data not only provide novel evidence of PRL actions at the SFO, but identify parameters of PRL signaling: PRL function is conserved independent of sexual maturity, sex, and estrous cyclicity of the animal and is independent of PRL concentration within the $10 \mathrm{pM}$ to $1 \mu \mathrm{M}$ range. 


\section{Reference List}

Abbott, N. J., Ronnback, L., \& Hansson, E. (2006). Astrocyte-endothelial interactions at the blood-brain barrier. Nat Rev Neurosci, 7(1), 41-53. https://doi.org/10.1038/nrn1824

Ahmed, A.-S. F., Dai, L., Ho, W., Ferguson, A. V., \& Sharkey, K. A. (2014). The subfornical organ: a novel site of action of cholecystokinin. American Journal of Physiology Regulatory, Integrative and Comparative Physiology, 306(5), R363. https://doi.org/10.1152/ajpregu.00462.2013

Antunes-Rodrigues, J., McCann, S. M., Rogers, L. C., \& Samson, W. K. (1985). Atrial natriuretic factor inhibits dehydration- and angiotensin II-induced water intake in the conscious, unrestrained rat. Proceedings of the National Academy of Sciences, 82(24), 8720-8723.

Augustine, R. A., Kokay, I. C., Andrews, Z. B., Ladyman, S. R., \& Grattan, D. R. (2003). Quantitation of prolactin receptor mRNA in the maternal rat brain during pregnancy and lactation. Journal of Molecular Endocrinology, 31(1), 221-232.

Baraboi, E.-D., Smith, P., Ferguson, A. V., \& Richard, D. (2010). Lesions of area postrema and subfornical organ alter exendin-4-induced brain activation without preventing the hypophagic effect of the GLP-1 receptor agonist. American Journal of Physiology Regulatory, Integrative and Comparative Physiology, 298(4), R1098. https://doi.org/10.1152/ajpregu.00326.2009

Bartke, A. (1974). Effects of inhibitors of pituitary prolactin release on testicular cholesterol stores, seminal vesicles weight, fertility, and lactation in mice. Biology of Reproduction, 11(3), 319-325.

Bates, R. W., \& Riddle, O. (1935). The Preparation of Prolactin. Journal of Pharmacology and Experimental Therapeutics, 55(3), 365.

Belugin, S., Diogenes, A. R., Patil, M. J., Ginsburg, E., Henry, M. A., \& Akopian, A. N. (2013). Mechanisms of Transient Signaling via Short and Long Prolactin Receptor Isoforms in 
Female and Male Sensory Neurons. Journal of Biological Chemistry, 288(48), 3494334955. https://doi.org/10.1074/jbc.M113.486571

Ben-Jonathan, N., Hugo, E. R., Brandebourg, T. D., \& LaPensee, C. R. (2006). Focus on prolactin as a metabolic hormone. Trends in Endocrinology \& Metabolism, 17(3), 110 116. https://doi.org/10.1016/j.tem.2006.02.005

Bern, H. A. (1975). Prolactin and Osmoregulation. American Zoologist, 15(4), 937-948. https://doi.org/10.1093/icb/15.4.937

Berne, R. M., Koeppen, B. M., \& Stanton, B. A. (Eds.). (2010). Berne \& Levy physiology (6th ed., updated ed). Philadelphia, PA: Mosby/Elsevier.

Biswas, S., \& Rodeck, C. H. (1976). Plasma prolactin levels during pregnancy. British Journal of Obstetrics and Gynaecology, 83(9), 683-687.

Bole-Feysot, C., Goffin, V., Edery, M., Binart, N., \& Kelly, P. A. (1998). Prolactin (PRL) and its receptor: actions, signal transduction pathways and phenotypes observed in PRL receptor knockout mice. Endocrine Reviews, 19(3), 225-268.

https://doi.org/10.1210/edrv.19.3.0334

Brandebourg, T. D., Bown, J. L., \& Ben-Jonathan, N. (2007). Prolactin upregulates its receptors and inhibits lipolysis and leptin release in male rat adipose tissue. Biochemical and Biophysical Research Communications, 357(2), 408-413. https://doi.org/10.1016/j.bbrc.2007.03.168

Breves, J. P., Inokuchi, M., Yamaguchi, Y., Seale, A. P., Hunt, B. L., Watanabe, S., ... Grau, E. G. (2016). Hormonal regulation of aquaporin 3: opposing actions of prolactin and cortisol in tilapia gill. The Journal of Endocrinology, 230(3), 325-337. https://doi.org/10.1530/JOE-16-0162

Breves, J. P., McCormick, S. D., \& Karlstrom, R. O. (2014). Prolactin and teleost ionocytes: new insights into cellular and molecular targets of prolactin in vertebrate epithelia. General 
and Comparative Endocrinology, 203, 21-28.

https://doi.org/10.1016/j.ygcen.2013.12.014

Brown, P. S., \& Brown, S. C. (1973). Prolactin and thyroid hormone interactions in salt and water balance in the newt Notophthalmus viridescens. General and Comparative Endocrinology, 20(3), 455-466.

Brown, R. S. E., Kokay, I. C., Herbison, A. E., \& Grattan, D. R. (2010). Distribution of prolactinresponsive neurons in the mouse forebrain. The Journal of Comparative Neurology, 518(1), 92-102. https://doi.org/10.1002/cne.22208

Cancelliere, N. M., \& Ferguson, A. V. (2017). Subfornical organ neurons integrate cardiovascular and metabolic signals. American Journal of Physiology - Regulatory, Integrative and Comparative Physiology, 312(2), R253-R262. https://doi.org/10.1152/ajpregu.00423.2016

Cannon, W. B. (1929). Organization for Physiological Homeostasis. Physiological Reviews, 9(3), 399.

Chiu, S., Koos, R. D., \& Wise, P. M. (1992). Detection of prolactin receptor (PRL-R) mRNA in the rat hypothalamus and pituitary gland. Endocrinology, 130(3), 1747-1749. https://doi.org/10.1210/endo.130.3.1537321

Conrad, K. P. (2011). Maternal vasodilation in pregnancy: the emerging role of relaxin. American Journal of Physiology - Regulatory, Integrative and Comparative Physiology, 301(2), R267. https://doi.org/10.1152/ajpregu.00156.2011

Cook, C. J. (1997). Oxytocin and prolactin suppress cortisol responses to acute stress in both lactating and non-lactating sheep. Journal of Dairy Research, 64(3), 327-339.

Cowley, M. A., Smart, J. L., Rubinstein, M., Cerdan, M. G., Diano, S., Horvath, T. L., ... Low, M. J. (2001). Leptin activates anorexigenic POMC neurons through a neural network in the arcuate nucleus. Nature, 411(6836), 480-484. https://doi.org/10.1038/35078085 
Dellmann, H. D., \& Simpson, J. B. (1976). Regional differences in the morphology of the rat subfornical organ. Brain Research, 116(3), 389-400.

Dharmamba, M., \& Maetz, J. (1972). Effects of hypophysectomy and prolactin on the sodium balance of Tilapia mossambica in fresh water. General and Comparative Endocrinology, 19(1), 175-183.

Di Carlo, R., Muccioli, G., Papotti, M., \& Bussolati, G. (1992). Characterization of prolactin receptor in human brain and choroid plexus. Brain Research, 570(1-2), 341-346.

Döhler, K. D., \& Wuttke, W. (1975). Changes with Age in Levels of Serum Gonadotropins, Prolactin, and Gonadal Steroids in Prepubertal Male and Female Rats. Endocrinology, 97(4), 898-907. https://doi.org/10.1210/endo-97-4-898

Donevan, S. D., Van Vugt, D. A., \& Ferguson, A. V. (1989). Subfornical organ activation stimulates luteinizing hormone secretion in the rat. Brain Research, 488(1-2), 398-402.

Dong, J., Tsai-Morris, C.-H., \& Dufau, M. L. (2006). A novel estradiol/estrogen receptor alphadependent transcriptional mechanism controls expression of the human prolactin receptor. The Journal of Biological Chemistry, 281(27), 18825-18836. https://doi.org/10.1074/jbc.M512826200

Dschietzig, T., Bartsch, C., Richter, C., Laule, M., Baumann, G., \& Stangl, K. (2003). Relaxin, a pregnancy hormone, is a functional endothelin-1 antagonist. Circulation Research, 92(1), $32-40$.

Egli, M., Leeners, B., \& Kruger, T. H. C. (2010). Prolactin secretion patterns: basic mechanisms and clinical implications for reproduction. Reproduction (Cambridge, England), 140(5), 643-654. https://doi.org/10.1530/REP-10-0033

Faouzi, M., Chopin, V., Ahidouch, A., \& Ouadid-Ahidouch, H. (2010). Intermediate Ca2+sensitive $\mathrm{K}+$ channels are necessary for prolactin-induced proliferation in breast cancer 
cells. The Journal of Membrane Biology, 234(1), 47-56. https://doi.org/10.1007/s00232010-9238-5

Ferguson, A. V., Bicknell, R. J., Carew, M. A., \& Mason, W. T. (1997). Dissociated adult rat subfornical organ neurons maintain membrane properties and angiotensin responsiveness for up to 6 days. Neuroendocrinology, 66(6), 409-415.

Ferguson, Alastair V., \& Li, Z. (1996). Whole cell patch recordings from forebrain slices demonstrate angiotensin II inhibits potassium currents in subfornical organ neurons. Regulatory Peptides, 66(1-2), 55-58. https://doi.org/10.1016/0167-0115(96)00049-3

Franceschini, I., Lomet, D., Cateau, M., Delsol, G., Tillet, Y., \& Caraty, A. (2006). Kisspeptin immunoreactive cells of the ovine preoptic area and arcuate nucleus co-express estrogen receptor alpha. Neuroscience Letters, 401(3), 225-230.

https://doi.org/10.1016/j.neulet.2006.03.039

Freeman, M. E., Kanyicska, B., Lerant, A., \& Nagy, G. (2000). Prolactin: structure, function, and regulation of secretion. Physiological Reviews, 80(4), 1523-1631.

Fujisawa, S., Tanaka, J., \& Nomura, M. (2001). Estrogen attenuates the drinking response induced by activation of angiotensinergic pathways from the lateral hypothalamic area to the subfornical organ in female rats. Behavioural Brain Research, 122(1), 33-41.

Ganong, W. F. (2000). Circumventricular organs: definition and role in the regulation of endocrine and autonomic function. Clinical and Experimental Pharmacology \& Physiology, 27(5-6), 422-427.

Goffin, V., Binart, N., Touraine, P., \& Kelly, P. A. (2002). Prolactin: the new biology of an old hormone. Annual Review of Physiology, 64, 47-67. https://doi.org/10.1146/annurev.physiol.64.081501.131049 
Golden, P. L., Maccagnan, T. J., \& Pardridge, W. M. (1997). Human blood-brain barrier leptin receptor. Binding and endocytosis in isolated human brain microvessels. The Journal of Clinical Investigation, 99(1), 14-18. https://doi.org/10.1172/JCI119125

Gordon, J., Amini, S., \& White, M. K. (2013). General overview of neuronal cell culture. Methods in Molecular Biology (Clifton, N.J.), 1078, 1-8. https://doi.org/10.1007/978-162703-640-5_1

Grachev, P., Li, X. F., Goffin, V., \& O’Byrne, K. T. (2015). Hypothalamic Prolactin Regulation of Luteinizing Hormone Secretion in the Female Rat. Endocrinology, 156(8), 2880-2892. https://doi.org/10.1210/en.2015-1040

Grattan, D. R., Jasoni, C. L., Liu, X., Anderson, G. M., \& Herbison, A. E. (2007). Prolactin Regulation of Gonadotropin-Releasing Hormone Neurons to Suppress Luteinizing Hormone Secretion in Mice. Endocrinology, 148(9), 4344-4351.

https://doi.org/10.1210/en.2007-0403

Gray, S. M., Aylor, K. W., \& Barrett, E. J. (2017). Unravelling the regulation of insulin transport across the brain endothelial cell. Diabetologia, 60(8), 1512-1521. https://doi.org/10.1007/s00125-017-4285-4

Greenman, Y., Tordjman, K., \& Stern, N. (1998). Increased body weight associated with prolactin secreting pituitary adenomas: weight loss with normalization of prolactin levels. Clinical Endocrinology, 48(5), 547-553.

Gustafson, P., Kokay, I., Sapsford, T., Bunn, S., \& Grattan, D. (2017). Prolactin regulation of the HPA axis is not mediated by a direct action upon CRH neurons: evidence from the rat and mouse. Brain Structure \& Function. https://doi.org/10.1007/s00429-017-1395-1

Gutman, M. B., Ciriello, J., \& Mogenson, G. J. (1988). Effects of plasma angiotensin II and hypernatremia on subfornical organ neurons. The American Journal of Physiology, 254(5 Pt 2), R746-754. 
Harris, A. R., Christianson, D., Smith, M. S., Fang, S. L., Braverman, L. E., \& Vagenakis, A. G. (1978). The physiological role of thyrotropin-releasing hormone in the regulation of thyroid-stimulating hormone and prolactin secretion in the rat. The Journal of Clinical Investigation, 61(2), 441-448. https://doi.org/10.1172/JCI108955

Hattori, Y., Kasai, M., Uesugi, S., Kawata, M., \& Yamashita, H. (1988). Atrial natriuretic polypeptide depresses angiotensin II induced excitation of neurons in the rat subfornical organ in vitro. Brain Research, 443(1-2), 355-359.

Helena, C. V., Cristancho-Gordo, R., Gonzalez-Iglesias, A. E., Tabak, J., Bertram, R., \& Freeman, M. E. (2011). Systemic oxytocin induces a prolactin secretory rhythm via the pelvic nerve in ovariectomized rats. American Journal of Physiology. Regulatory, Integrative and Comparative Physiology, 301(3), R676-681. https://doi.org/10.1152/ajpregu.00176.2011

Hindmarch, C., Fry, M., Yao, S. T., Smith, P. M., Murphy, D., \& Ferguson, A. V. (2008). Microarray analysis of the transcriptome of the subfornical organ in the rat: regulation by fluid and food deprivation. American Journal of Physiology - Regulatory, Integrative and Comparative Physiology, 295(6), R1914-R1920.

https://doi.org/10.1152/ajpregu.90560.2008

Hirahara, F., Andoh, N., Sawai, K., Hirabuki, T., Uemura, T., \& Minaguchi, H. (1998).

Hyperprolactinemic recurrent miscarriage and results of randomized bromocriptine treatment trials. Fertility and Sterility, 70(2), 246-252.

Horrobin, D. F., Lloyd, I. J., Lipton, A., Burstyn, P. G., Durkin, N., \& Muiruri, K. L. (1971). Actions of prolactin on human renal function. Lancet (London, England), 2(7720), 352354.

Horseman, N. D., Zhao, W., Montecino-Rodriguez, E., Tanaka, M., Nakashima, K., Engle, S. J., ... Dorshkind, K. (1997). Defective mammopoiesis, but normal hematopoiesis, in mice 
with a targeted disruption of the prolactin gene. The EMBO Journal, 16(23), 6926-6935. https://doi.org/10.1093/emboj/16.23.6926

Ikezu, T. (2016). Neuroimmune pharmacology. New York, NY: Springer Science+Business Media.

Johnson, A. K. (1985). The periventricular anteroventral third ventricle (AV3V): its relationship with the subfornical organ and neural systems involved in maintaining body fluid homeostasis. Brain Research Bulletin, 15(6), 595-601.

Johnson, A. K., \& Gross, P. M. (1993). Sensory circumventricular organs and brain homeostatic pathways. FASEB Journal: Official Publication of the Federation of American Societies for Experimental Biology, 7(8), 678-686.

Kakouris, H., Eddie, L. W., \& Summers, R. J. (1992). Cardiac effects of relaxin in rats. Lancet (London, England), 339(8801), 1076-1078.

Kaufman, S. (1981). The dipsogenic activity of prolactin in male and female rats. The Journal of Physiology, 310(1), 435-444. https://doi.org/10.1113/jphysiol.1981.sp013559

Kaufman, S., \& Mackay, B. J. (1983). Plasma prolactin levels and body fluid deficits in the rat: causal interactions and control of water intake. The Journal of Physiology, 336, 73-81.

Kauppila, A., Chatelain, P., Kirkinen, P., Kivinen, S., \& Ruokonen, A. (1987). Isolated prolactin deficiency in a woman with puerperal alactogenesis. The Journal of Clinical Endocrinology and Metabolism, 64(2), 309-312. https://doi.org/10.1210/jcem-64-2-309

Kavarthapu, R., Tsai Morris, C.-H., \& Dufau, M. L. (2014). Prolactin induces up-regulation of its cognate receptor in breast cancer cells via transcriptional activation of its generic promoter by cross-talk between ER $\alpha$ and STAT5. Oncotarget, 5(19), 9079-9091. https://doi.org/10.18632/oncotarget.2376 
Kawano, H., \& Masuko, S. (2010). Region-specific projections from the subfornical organ to the paraventricular hypothalamic nucleus in the rat. Neuroscience, 169(3), 1227-1234. https://doi.org/10.1016/j.neuroscience.2010.05.065

Kennedy, G. C. (1950). The hypothalamic control of food intake in rats. Proceedings of the Royal Society of London. Series B, Biological Sciences, 137(889), 535-549.

Krohn, P. L., \& Zuckerman, S. (1937). Water metabolism in relation to the menstrual cycle. The Journal of Physiology, 88(4), 369-387.

Kuksis, M., \& Ferguson, A. V. (2015). Actions of a hydrogen sulfide donor (NaHS) on transient sodium, persistent sodium, and voltage-gated calcium currents in neurons of the subfornical organ. Journal of Neurophysiology, 114(3), 1641-1651. https://doi.org/10.1152/jn.00252.2015

Larsen, C. M., \& Grattan, D. R. (2010). Prolactin-induced mitogenesis in the subventricular zone of the maternal brain during early pregnancy is essential for normal postpartum behavioral responses in the mother. Endocrinology, 151(8), 3805-3814. https://doi.org/10.1210/en.2009-1385

Leav, I., Merk, F. B., Lee, K. F., Loda, M., Mandoki, M., McNeal, J. E., \& Ho, S. M. (1999). Prolactin receptor expression in the developing human prostate and in hyperplastic, dysplastic, and neoplastic lesions. The American Journal of Pathology, 154(3), 863-870. https://doi.org/10.1016/S0002-9440(10)65333-3

Leontic, E. A., \& Tyson, J. E. (1977). Prolactin and fetal osmoregulation: water transport across isolated human amnion. The American Journal of Physiology, 232(3), R124-127.

Limonta, P., Maggi, R., Giudici, D., Martini, L., \& Piva, F. (1981). Role of the subfornical organ (SFO) in the control of gonadotropin secretion. Brain Research, 229(1), 75-84. https://doi.org/10.1016/0006-8993(81)90747-2 
Linley, J. (2013). Perforated Whole-Cell Patch-Clamp Recording. In N. Gamper (Ed.), Ion Channels (pp. 149-157). Humana Press. https://doi.org/10.1007/978-1-62703-351-0_11

Lopez-Fontana, C. M., Maselli, M. E., de Di Nasso, F. E. G., Telleria, C. M., \& Caron, R. W. (2011). Regulation of prolactin secretion during the estrus in rats: possible role of glucocorticoids. Reproduction (Cambridge, England), 142(3), 477-485. https://doi.org/10.1530/REP-11-0100

Lyons, D. J., Hellysaz, A., \& Broberger, C. (2012). Prolactin regulates tuberoinfundibular dopamine neuron discharge pattern: novel feedback control mechanisms in the lactotrophic axis. The Journal of Neuroscience : The Official Journal of the Society for Neuroscience, 32(23), 8074-8083. https://doi.org/10.1523/JNEUROSCI.0129-12.2012

Mangiapane, M. L., \& Simpson, J. B. (1980). Subfornical organ lesions reduce the pressor effect of systemic angiotensin II. Neuroendocrinology, 31(6), 380-384.

Matthes, F., Wolte, P., Bockenhoff, A., Huwel, S., Schulz, M., Hyden, P., ... Matzner, U. (2011). Transport of arylsulfatase A across the blood-brain barrier in vitro. The Journal of Biological Chemistry, 286(20), 17487-17494. https://doi.org/10.1074/jbc.M110.189381

McNeilly, A. S., Abbott, D. H., Lunn, S. F., Chambers, P. C., \& Hearn, J. P. (1981). Plasma prolactin concentrations during the ovarian cycle and lactation and their relationship to return of fertility post-partum in the common marmoset (Callithrix jacchus). Journal of Reproduction and Fertility, 62(2), 353-360.

Medeiros, N., Dai, L., \& Ferguson, A. V. (2012). Glucose-responsive neurons in the subfornical organ of the rat--a novel site for direct CNS monitoring of circulating glucose. Neuroscience, 201, 157-165. https://doi.org/10.1016/j.neuroscience.2011.11.028

Merrill, J. E., \& Jonakait, G. M. (1995). Interactions of the nervous and immune systems in development, normal brain homeostasis, and disease. FASEB Journal: Official 
Publication of the Federation of American Societies for Experimental Biology, 9(8), $611-618$.

Miselis, R. R., Shapiro, R. E., \& Hand, P. J. (1979). Subfornical organ efferents to neural systems for control of body water. Science (New York, N.Y.), 205(4410), 1022-1025.

Miselis, R. R. (1981). The efferent projections of the subfornical organ of the rat: A circumventricular organ within a neural network subserving water balance. Brain Research, 230(1-2), 1-23. https://doi.org/10.1016/0006-8993(81)90388-7

Moorman, B. P., Inokuchi, M., Yamaguchi, Y., Lerner, D. T., Grau, E. G., \& Seale, A. P. (2014). The osmoregulatory effects of rearing Mozambique tilapia in a tidally changing salinity. General and Comparative Endocrinology, 207, 94-102. https://doi.org/10.1016/j.ygcen.2014.03.013

Morita, S., \& Miyata, S. (2012). Different vascular permeability between the sensory and secretory circumventricular organs of adult mouse brain. Cell and Tissue Research, 349(2), 589-603. https://doi.org/10.1007/s00441-012-1421-9

Nagaishi, V. S., Cardinali, L. I., Zampieri, T. T., Furigo, I. C., Metzger, M., \& Donato, J. (2014). Possible crosstalk between leptin and prolactin during pregnancy. Neuroscience, 259, 7183. https://doi.org/10.1016/j.neuroscience.2013.11.050

Neumann, I. D., Johnstone, H. A., Hatzinger, M., Liebsch, G., Shipston, M., Russell, J. A., ... Douglas, A. J. (1998). Attenuated neuroendocrine responses to emotional and physical stressors in pregnant rats involve adenohypophysial changes. The Journal of Physiology, 508 (Pt 1), 289-300.

Novak, J., Danielson, L. A., Kerchner, L. J., Sherwood, O. D., Ramirez, R. J., Moalli, P. A., \& Conrad, K. P. (2001). Relaxin is essential for renal vasodilation during pregnancy in conscious rats. The Journal of Clinical Investigation, 107(11), 1469-1475. https://doi.org/10.1172/JCI11975 
Ocłoń, E., Lesniak-Walentyn, A., Solomon, G., Shpilman, M., Hrabia, A., \& Gertler, A. (2017). Comparison of in vitro bioactivity of chicken prolactin and mammalian lactogenic hormones. General and Comparative Endocrinology, 240, 27-34. https://doi.org/10.1016/j.ygcen.2016.09.008

Ogawa, M., Yagasaki, M., \& Yamazaki, F. (1973). The effect of prolactin on water influx in isolated gills of the goldfish, Carassius auratus L. Comparative Biochemistry and Physiology. A, Comparative Physiology, 44(4), 1177-1183.

Ono, K., Honda, E., \& Inenaga, K. (2001). Angiotensin II induces inward currents in subfornical organ neurones of rats. Journal of Neuroendocrinology, 13(6), 517-523.

Otsubo, H., Onaka, T., Suzuki, H., Katoh, A., Ohbuchi, T., Todoroki, M., ... Ueta, Y. (2010). Centrally administered relaxin-3 induces Fos expression in the osmosensitive areas in rat brain and facilitates water intake. Peptides, 31(6), 1124-1130.

https://doi.org/10.1016/j.peptides.2010.02.020

Otto, C., Sarnefalt, A., Ljungars, A., Wolf, S., Rohde-Schulz, B., Fuchs, I., ... Freiberg, C. (2015). A Neutralizing Prolactin Receptor Antibody Whose In Vivo Application Mimics the Phenotype of Female Prolactin Receptor-Deficient Mice. Endocrinology, 156(11), 4365-4373. https://doi.org/10.1210/en.2015-1277

Park, S., Kang, S., Lee, H.-W., \& Ko, B. S. (2012). Central prolactin modulates insulin sensitivity and insulin secretion in diabetic rats. Neuroendocrinology, 95(4), 332-343. https://doi.org/10.1159/000336501

Park, S., Kim, D. S., Daily, J. W., \& Kim, S.-H. (2011). Serum prolactin concentrations determine whether they improve or impair beta-cell function and insulin sensitivity in diabetic rats. Diabetes/Metabolism Research and Reviews, 27(6), 564-574. https://doi.org/10.1002/dmrr.1215 
Patil, M. J., Henry, M. A., \& Akopian, A. N. (2014). Prolactin receptor in regulation of neuronal excitability and channels. Channels (Austin, Tex.), 8(3), 193-202.

Paton, J. F., Deuchars, J., Ahmad, Z., Wong, L. F., Murphy, D., \& Kasparov, S. (2001). Adenoviral vector demonstrates that angiotensin II-induced depression of the cardiac baroreflex is mediated by endothelial nitric oxide synthase in the nucleus tractus solitarii of the rat. The Journal of Physiology, 531(Pt 2), 445-458.

Paton, J. F. R., Wang, S., Polson, J. W., \& Kasparov, S. (2008). Signalling across the blood brain barrier by angiotensin II: novel implications for neurogenic hypertension. Journal of Molecular Medicine (Berlin, Germany), 86(6), 705-710. https://doi.org/10.1007/s00109008-0324-4

Perkins, N. A., Westfall, T. C., Paul, C. V., MacLeod, R., \& Rogol, A. D. (1979). Effect of prolactin on dopamine synthesis in medial basal hypothalamus: evidence for a short loop feedback. Brain Research, 160(3), 431-444.

Pfaffl, M. W. (2001). A new mathematical model for relative quantification in real-time RT-PCR. Nucleic Acids Research, 29(9), e45.

Pi, X., Zhang, B., Li, J., \& Voogt, J. L. (2003). Promoter usage and estrogen regulation of prolactin receptor gene in the brain of the female rat. Neuroendocrinology, 77(3), 187197. https://doi.org/69510

Pi, X.-J., \& Grattan, D. R. (1998). Distribution of prolactin receptor immunoreactivity in the brain of estrogen-treated, ovariectomized rats. Journal of Comparative Neurology, 394(4), 462-474.

Plant, T. M., Krey, L. C., Moossy, J., McCormack, J. T., Hess, D. L., \& Knobil, E. (1978). The arcuate nucleus and the control of gonadotropin and prolactin secretion in the female rhesus monkey (Macaca mulatta). Endocrinology, 102(1), 52-62. https://doi.org/10.1210/endo-102-1-52 
Pulman, K. J., Fry, W. M., Cottrell, G. T., \& Ferguson, A. V. (2006). The subfornical organ: a central target for circulating feeding signals. The Journal of Neuroscience: The Official Journal of the Society for Neuroscience, 26(7), 2022-2030.

https://doi.org/10.1523/JNEUROSCI.3218-05.2006

Puntheeranurak, S., Schreiber, R., Spitzner, M., Ousingsawat, J., Krishnamra, N., \& Kunzelmann, K. (2007). Control of ion transport in mouse proximal and distal colon by prolactin. Cellular Physiology and Biochemistry: International Journal of Experimental Cellular Physiology, Biochemistry, and Pharmacology, 19(1-4), 77-88. https://doi.org/10.1159/000099194

Ramaley, J. A. (1981). Serum prolactin levels in the prepubertal period in male and female rats. Control by photoperiod and gonadal status and relationship to puberty onset. International Journal of Andrology, 4(1), 91-104.

Rawn, S. M., Huang, C., Hughes, M., Shaykhutdinov, R., Vogel, H. J., \& Cross, J. C. (2015). Pregnancy Hyperglycemia in Prolactin Receptor Mutant, but Not Prolactin Mutant, Mice and Feeding-Responsive Regulation of Placental Lactogen Genes Implies Placental Control of Maternal Glucose Homeostasis. Biology of Reproduction, 93(3), 75. https://doi.org/10.1095/biolreprod.115.132431

Raymond, V., Beaulieu, M., Labrie, F., \& Boissier, J. (1978). Potent antidopaminergic activity of estradiol at the pituitary level on prolactin release. Science (New York, N.Y.), 200(4346), 1173-1175.

Rivero-Segura, N. A., Flores-Soto, E., García de la Cadena, S., Coronado-Mares, I., GomezVerjan, J. C., Ferreira, D. G., ... Cerbón, M. (2017). Prolactin-induced neuroprotection against glutamate excitotoxicity is mediated by the reduction of [Ca2+]i overload and NF-kB activation. PloS One, 12(5), e0176910.

https://doi.org/10.1371/journal.pone.0176910 
Rosas-Arellano, M. P., Solano-Flores, L. P., \& Ciriello, J. (1996). Neurotensin projections to subfornical organ from arcuate nucleus. Brain Research, 706(2), 323-327.

Rosas-Arellano, M. P., Solano-Flores, L. P., \& Ciriello, J. (1999). Co-localization of estrogen and angiotensin receptors within subfornical organ neurons. Brain Research, 837(1-2), 254262.

Sangiao-Alvarellos, S., Arjona, F. J., Míguez, J. M., Martín del Río, M. P., Soengas, J. L., \& Mancera, J. M. (2006). Growth hormone and prolactin actions on osmoregulation and energy metabolism of gilthead sea bream (Sparus auratus). Comparative Biochemistry and Physiology Part A: Molecular \& Integrative Physiology, 144(4), 491-500. https://doi.org/10.1016/j.cbpa.2006.04.015

Sapsford, T. J., Kokay, I. C., Ostberg, L., Bridges, R. S., \& Grattan, D. R. (2012). Differential sensitivity of specific neuronal populations of the rat hypothalamus to prolactin action. The Journal of Comparative Neurology, 520(5), 1062-1077. https://doi.org/10.1002/cne.22775

Sauvé, D., \& Woodside, B. (1996). The effect of central administration of prolactin on food intake in virgin female rats is dose-dependent, occurs in the absence of ovarian hormones and the latency to onset varies with feeding regimen. Brain Research, 729(1), 75-81.

Sauvé, Danielle, \& Woodside, B. (2000). Neuroanatomical specificity of prolactin-induced hyperphagia in virgin female rats. Brain Research, 868(2), 306-314. https://doi.org/10.1016/S0006-8993(00)02344-1

Shaver, S. W., Sposito, N. M., \& Gross, P. M. (1990). Quantitative fine structure of capillaries in subregions of the rat subfornical organ. The Journal of Comparative Neurology, 294(1), 145-152. https://doi.org/10.1002/cne.902940111 
Sheridan, M. A. (1986). Effects of thyroxin, cortisol, growth hormone, and prolactin on lipid metabolism of coho salmon, Oncorhynchus kisutch, during smoltification. General and Comparative Endocrinology, 64(2), 220-238.

Shu, Y., Lou, Q., Dai, Z., Dai, X., He, J., Hu, W., \& Yin, Z. (2016). The basal function of teleost prolactin as a key regulator on ion uptake identified with zebrafish knockout models. Scientific Reports, 6, 18597. https://doi.org/10.1038/srep18597

Silveira, M. A., Furigo, I. C., Zampieri, T. T., Bohlen, T. M., de Paula, D. G., Franci, C. R., ... Frazao, R. (2017). STAT5 signaling in kisspeptin cells regulates the timing of puberty. Molecular and Cellular Endocrinology, 448, 55-65. https://doi.org/10.1016/j.mce.2017.03.024

Silveyra, P., Catalano, P. N., Lux-Lantos, V., \& Libertun, C. (2007). Impact of proestrous milieu on expression of orexin receptors and prepro-orexin in rat hypothalamus and hypophysis: actions of Cetrorelix and Nembutal. American Journal of Physiology. Endocrinology and Metabolism, 292(3), E820-828. https://doi.org/10.1152/ajpendo.00467.2006

Simpson, J. B., Epstein, A. N., \& Camardo, J. S. J. (1978). Localization of receptors for the dipsogenic action of angiotensin II in the subfornical organ of rat. Journal of Comparative and Physiological Psychology, 92(4), 581-601.

Sirzen-Zelenskaya, A., Gonzalez-Iglesias, A. E., de Monvel, J. B., Bertram, R., Freeman, M. E., Gerber, U., \& Egli, M. (2011). Prolactin induces a hyperpolarizing current in rat paraventricular oxytocinergic neurons. Journal of Neuroendocrinology, 23(10), 883-893. https://doi.org/10.1111/j.1365-2826.2011.02207.x

Sisó, S., Jeffrey, M., \& Gonzalez, L. (2010). Sensory circumventricular organs in health and disease. Acta Neuropathologica, 120(6), 689-705. https://doi.org/10.1007/s00401-010$0743-5$ 
Smith, P. M., Rozanski, G., \& Ferguson, A. V. (2010). Acute electrical stimulation of the subfornical organ induces feeding in satiated rats. Physiology \& Behavior, 99(4), 534537. https://doi.org/10.1016/j.physbeh.2010.01.013

Spanos, E., Colston, K. W., Evans, I. M., Galante, L. S., Macauley, S. J., \& Macintyre, I. (1976). Effect of prolactin on vitamin D metabolism. Molecular and Cellular Endocrinology, 5(3-4), 163-167.

Strader, A. D., \& Buntin, J. D. (2001). Neuropeptide-Y: a possible mediator of prolactin-induced feeding and regulator of energy balance in the ring dove (Streptopelia risoria). Journal of Neuroendocrinology, 13(4), 386-392.

Sunn, N., Egli, M., Burazin, T. C. D., Burns, P., Colvill, L., Davern, P., ... McKinley, M. J. (2002). Circulating relaxin acts on subfornical organ neurons to stimulate water drinking in the rat. Proceedings of the National Academy of Sciences of the United States of America, 99(3), 1701-1706. https://doi.org/10.1073/pnas.022647699

Surkin, P. N., Di Rosso, M. E., Correa, F., Elverdin, J. C., Genaro, A. M., De Laurentiis, A., \& Fernandez-Solari, J. (2017). Participation of hypothalamic CB1 receptors in reproductive axis disruption during immune challenge. Journal of Neuroendocrinology, 29(8). https://doi.org/10.1111/jne.12499

Swanson, L. W., \& Sawchenko, P. E. (1983). Hypothalamic integration: organization of the paraventricular and supraoptic nuclei. Annual Review of Neuroscience, 6, 269-324. https://doi.org/10.1146/annurev.ne.06.030183.001413

Tanaka, J., Miyakubo, H., Okumura, T., Sakamaki, K., \& Hayashi, Y. (2001). Estrogen decreases the responsiveness of subfornical organ neurons projecting to the hypothalamic paraventricular nucleus to angiotensin II in female rats. Neuroscience Letters, 307(3), $155-158$. 
Tay, C. C., Glasier, A. F., \& McNeilly, A. S. (1996). Twenty-four hour patterns of prolactin secretion during lactation and the relationship to suckling and the resumption of fertility in breast-feeding women. Human Reproduction (Oxford, England), 11(5), 950-955.

Torner, L., Toschi, N., Nava, G., Clapp, C., \& Neumann, I. D. (2002). Increased hypothalamic expression of prolactin in lactation: involvement in behavioural and neuroendocrine stress responses. The European Journal of Neuroscience, 15(8), 1381-1389.

Voisin, D. L., Simonian, S. X., \& Herbison, A. E. (1997). Identification of estrogen receptorcontaining neurons projecting to the rat supraoptic nucleus. Neuroscience, 78(1), 215228.

Voogt, J. L., Chen, C. L., \& Meites, J. (1970). Serum and pituitary prolactin levels before, during, and after puberty in female rats. The American Journal of Physiology, 218(2), 396-399.

Wall, K. M., \& Ferguson, A. V. (1992). Endothelin acts at the subfornical organ to influence the activity of putative vasopressin and oxytocin-secreting neurons. Brain Research, 586(1), $111-116$.

Walsh, R. J., Slaby, F. J., \& Posner, B. I. (1987). A receptor-mediated mechanism for the transport of prolactin from blood to cerebrospinal fluid. Endocrinology, 120(5), 18461850. https://doi.org/10.1210/endo-120-5-1846

Washburn, D. L., Beedle, A. M., \& Ferguson, A. V. (1999). Inhibition of subfornical organ neuronal potassium channels by vasopressin. Neuroscience, 93(1), 349-359.

Watanabe, S., Itoh, K., \& Kaneko, T. (2016). Prolactin and cortisol mediate the maintenance of hyperosmoregulatory ionocytes in gills of Mozambique tilapia: Exploring with an improved gill incubation system. General and Comparative Endocrinology, 232, 151159. https://doi.org/10.1016/j.ygcen.2016.04.024 
Wennbo, H., Kindblom, J., Isaksson, O. G., \& Tornell, J. (1997). Transgenic mice overexpressing the prolactin gene develop dramatic enlargement of the prostate gland. Endocrinology, 138(10), 4410-4415. https://doi.org/10.1210/endo.138.10.5461

Wu, W., Sun, M., Zhang, H.-P., Chen, T., Wu, R., Liu, C., .. Yang, P.-C. (2014). Prolactin mediates psychological stress-induced dysfunction of regulatory $\mathrm{T}$ cells to facilitate intestinal inflammation. Gut, 63(12), 1883-1892. https://doi.org/10.1136/gutjnl-2013306083

Young, C. N., Morgan, D. A., Butler, S. D., Mark, A. L., \& Davisson, R. L. (2013). The brain subfornical organ mediates leptin-induced increases in renal sympathetic activity but not its metabolic effects. Hypertension (Dallas, Tex.: 1979), 61(3), 737-744.

https://doi.org/10.1161/HYPERTENSIONAHA.111.00405 